\title{
Büyük Menderes Deltası'nın Kuzeyinde Yapılan Delgi Sondajlarda Mikropaleontolojik Bulgular
}

\section{Micropaleontological findings in core drillings in the northern part of the Büyük Menderes Delta}

Rifat İlhan*a, Ertuğ Önerb

\begin{tabular}{l} 
MakaleBilgisi \\
\hline DOI: \\
10.33688/aucbd.558247 \\
\hline MakaleGeçmişi: \\
Geliş: 26.04.2019 \\
Kabul: 24.08.2019 \\
\hline AnahtarKelimeler: \\
Büyük Menderes Deltas1 \\
Paleocoğrafya \\
Mikropaleontoloji \\
Ostrakod \\
Foraminifer
\end{tabular}

\section{Article Info}

DOI:

10.33688/aucbd.558247

Article History:

Received: 26.04.2019

Accepted: 24.08.2019

Keywords:

Büyük Menderes Delta

Paleogeography

Micropaleontology

Ostracoda

Foraminifera $\ddot{\partial} z$

Büyük Menderes Deltası'nın kuzeyinde yer alan Samsun Dă̆ı'nın güney yamaçlarındaki birikinti konilerinin Holosen'deki gelişimlerini ortaya koyabilmek, konileri oluşturan havzaların fiziki coğrafya özellikleri ile ilişkilendirebilmek amacıyla gerçekleştirilen çalışmada 30 adet alüvyal delgi sondaj yapılmıştır. Sondajlar, birikinti konileri ile ova yüzeyinin kesiştiği yerlerde yapılmış olup derinlikleri 2,70 m ile $23 \mathrm{~m}$ arasında değişmektedir. Sondajların farkl seviyelerinden sedimantolojik ve paleontolojik analizler için örnekler alınmıştır. Sondajlardan alınan örneklerin sedimantolojik ve paleontolojik analizleri ile sediman özellikleri ayrıntılı bir şekilde ortaya konulmuştur. Sedimanlar; flüvyal, geçiş ve denizel olmak üzere 3 ana birime ayrılmıştır. Bu birimlerin ayrlmasında sedimantolojik verilerin yanı sira paleontolojik veriler (Ostrakodlar, foraminiferler, gastropodlar ve bivalvialar) indikatör olarak kullanılmıştır. Söz konusu çalışmada incelenen 834 farklı seviyede bulunan ve değişen ortam koşullarının belirlenmesinde, sediman birimlerinin ayrılmasında indikatör olarak kullanılan mikropaleontolojik (Ostrakodlar ve foraminiferler) bulgular burada sunulmuştur.

\begin{abstract}
In the study which was carried out to reveal the development of the alluvial cones in the southern slopes of the Mount Samsun located to the north of the Büyük Menderes Delta in Holocene and associate it with the physical geographical characteristics of the basins that form the cones, 30 alluvial core drilling were utilized. The core drilling were made at the intersection of the deposit cones and the plain surface and their depths ranges between $2.70 \mathrm{~m}$ and $23 \mathrm{~m}$. Samples were taken from different levels of the core drilling for sedimentological and paleontological analyses. With the sedimentological and paleontological analyses of the samples taken from the core drilling, sediment characteristics were determined in detail. The sediments were divided into 3 main units as fluvial, transition and marine. While separating these units, in addition to sedimentological data, paleontological data were also used as an indicator. This study presents the micropaleontological findings that were used as an indicator for determining the environmental conditions found on the 834 different levels examined in the study and separating the sediment units.
\end{abstract}

\footnotetext{
*Sorumlu Yazar/Corresponding Author: Rifat İlhan, rifatcografya@gmail.com

aAdıyaman Üniversitesi, Fen-Edebiyat Fakültesi, Coğrafya Bölümü, Adıyaman, Türkiye, http://orcid.org/0000-0001-83929349

bEge Üniversitesi, Edebiyat Fakültesi, Coğrafya Bölümü, İzmir, Türkiye, http://orcid.org/0000-0002-9712-5277
} 


\section{Giris}

Mikropalentoloji, Paleontolojinin mikrofosilleri inceleyen bir alt bölümüdür. Mikrofosiller, genellikle mikron boyutunda olmaları nedeniyle mikroskop gibi bir büyültücü kullanılarak görülebilmekte ve incelenebilmektedir. Jeolojik çağların farklı dönemlerinde farklı ortamlarda yaşamış olan mikroskobik canlıların kullanım alanların çeşitlenmesi mikropaleontolojinin önemini gün geçtikçe arttırmaktadır (Erdoğan, 1993; İnan, 2009).

Farklı alanlardaki çalışmalarda kullanılan mikropaleontolojik veriler günümüzde doğal çevrede meydana gelen değişmelerin belirlenmesinde başvurulan temel veri konumundadır. Mikropaleontolojik analizlerin temel veri kaynağı olması canlıların bulundukları ortamı yansıtmaları ile ilişkilidir. Çünkü her canlı kendine has bir takım özellikler ile farklı ortamlarda (karasal, denizel, lagün, bataklık, göl, hafif tuzlu su, tatlı su gibi) yaşamaktadır. Dolayısıyla farklı ortamlarda yaşamış canlılara ait fosiller ile canlının yaşadığı ortam belirlenebilmekte ve geçmişe yönelik değerlendirmeler yapılabilmektedir. Özellikle sedimanlar içerisinde daha iyi korunabilen ve bol miktarda bulunan mikrofosiller ortam hakkında oldukça güvenilir bilgiler sağlamaktadır (Barbieri ve Vaiani, 2018; Boomer vd., 2003; Murray, 2000; Murray, 2006). Yaşam ortamında fosilleri kalan canlılar bu açıdan çok daha önemlidir. Örneğin bentik foraminiferler bu tip canlılardır.

Son dönemde mikropaleontolojik (Ostrakod ve foraminifer) verilerden yararlanılarak birçok çalışma yapışmıştır. Bu çalışmaların özellikle deltalar ve kıyı alanlarında yoğunlaştığı görülmektedir. Doğal çevrenin daha hızlı değiştiği alanları olan deltalar ve kıyılarda bu değişimlerin belirlenmesinde mikropaleontolojik veriler ortam özelliklerini (Tatlı su, hafif tuzlu su, bataklık, lagün, denizel) yansıtan indikatör (Gösterge) konumundadır. Dolayısıyla bu gibi çalışmalarda mikropaleontolojik veriler bu amaç ile kullanılmıştır (Akbulut ve Öner, 2015; Armstrong ve Brasier, 2005; Gökçen, 1976; İlhan, 2017; Karadaş, 2014; Kayan, 2015; Kayan ve Öner, 2015; Müllenhoff vd., 2004; Öner vd., 2013; Öner ve Akbulut, 2015; Öner, 2016; Öner vd., 2018; Vardar, 2010; Vardar ve Öner, 2017; Vardar vd., 2017; Vardar, 2018; Yıldız ve Öner, 2015).

Büyük Menderes Deltası'nın kuzeyinde yer alan Samsun Dağı'nın güney yamaçlarındaki birikinti konilerinin Holosen'deki gelişimlerini ortaya koyabilmek, konileri oluşturan havzaların fiziki coğrafya özellikleri ile ilişkilendirebilmek amacıyla yapılan çalışma kapsamında alüvyal delgi sondajlar yapılmıştır (İlhan, 2017; Şekil 1). Yapılan sondajlardan alınan örneklerin sedimantolojik ve paleontolojik analizleri ile sediman özellikleri ayrıntılı bir şekilde incelenmiştir. Sedimanlar; flüvyal, geçiş ve denizel olmak üzere 3 ana birime ayrılmıştır. Bu birimlerin ayrılmasında paleontolojik veriler (Ostrakodlar, foraminiferler, gastropodlar ve bivalvialar) indikatör olarak kullanılmıştır. Burada söz konusu çalışmada bulunan ve değişen ortam koşullarının belirlenmesinde, sediman birimlerinin ayrılmasında bir indikatör olarak kullanılan mikropaleontolojik (Ostrakodlar ve foraminiferler) bulgular sunulmuştur. 


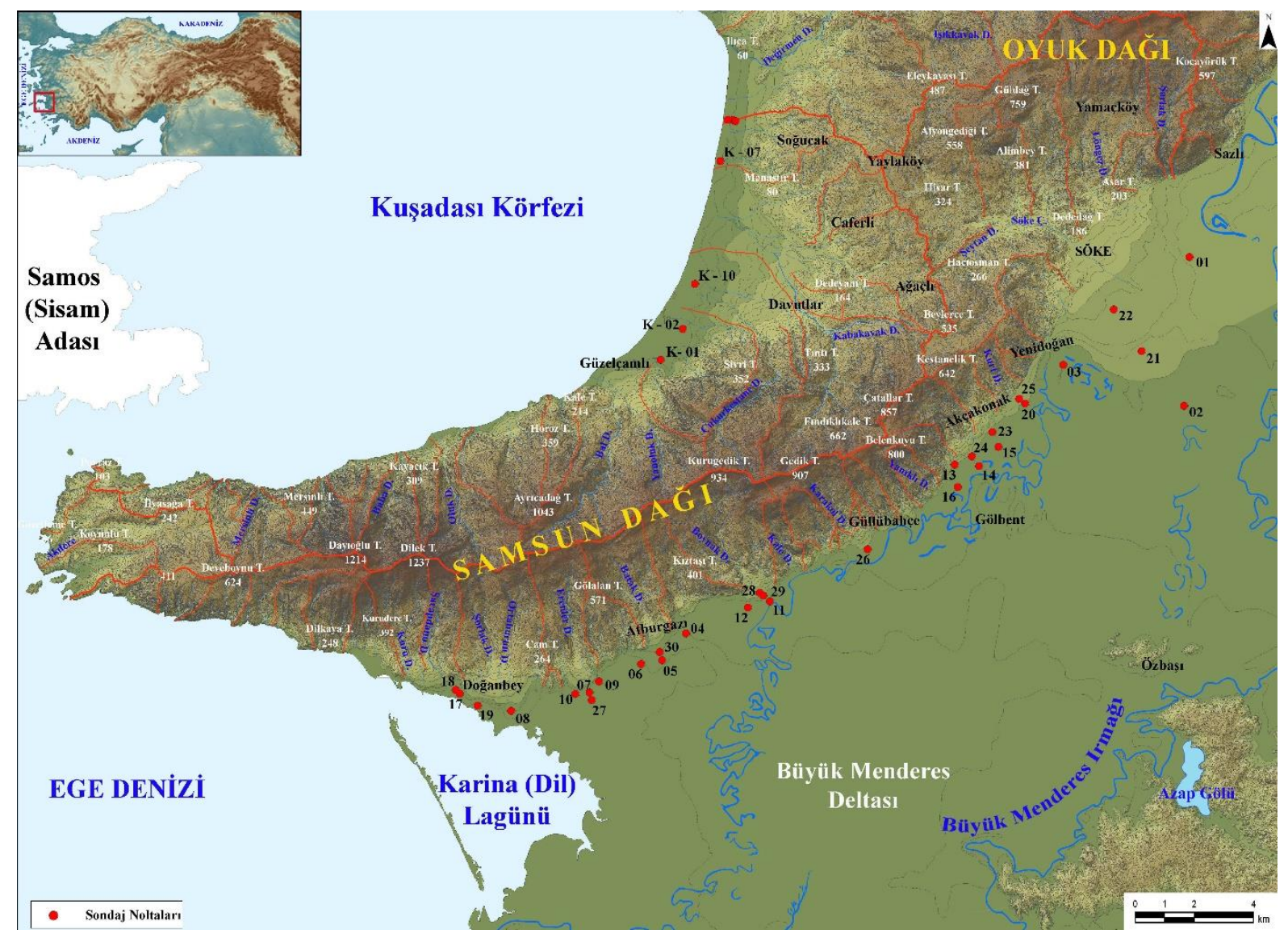

Şekil 1. Çalışma alanının lokasyonu ve sondaj noktaları (Kırmızı noktalar sondaj yerlerini, sayılar sondaj numarasını göstermektedir. K ile başlayan sondajlar ise Kadıkalesi ve çevresinde yapılan sondajları göstermektedir).

Kaynak: İlhan, 2017.

\section{Materyal ve Yöntem}

Çalışmada verilerimizi oluşturan sediman örnekleri Samsun Dağı'nın güneyinde yer alan birikinti konileri ile ova yüzeyinin kesiştiği noktalarda yapılan alüvyal delgi sondajlarından alınmıştır (Şekil 1). Üzerindeki yerleşmeler ile adlandırılan faklı boyutlardaki bu koniler: Söke, Akçakonak (Gümelez), Güllübahçe, Boynak, Atburgazı, Tuzburgazı, Doğanbey ve Dalyan birikinti konileridir. Samsun Dağı'nın güneyinde yapılan ve bu çalışmanın temel verilerinin sağlandığı alüvyal delgi sondajlar farklı dönemlerde farklı noktalarda yapılmış olup, yapılma sırasına göre $(01,02,03 \mathrm{vb}$. şekilde) numaralandırılmıştır. Samsun Dă̆ı'nın kuzeyinde K-sondaj numarası ile gösterilen sondaj noktaları ise Kadıkalesi ve çevresindeki Paleocoğrafya - Jeoarkeoloji çalışmaları kapsamında yapılan sondajları göstermektedir (İlhan, 2017; Yıldız ve Öner, 2015; Şekil 1).

Sondajlar, Ege Üniversitesi Coğrafya Bölümü’ne ait değişik özellikteki ekipmanlar kullanılarak yapılmıştır (Şekil 2). Farklı dönemlerde yapılan sondajların büyük bir bölümünde günümüz deniz seviyesinin altına inilmiştir. Sondajların derinlikleri yüzeyden itibaren $270 \mathrm{~cm}$ ile $2300 \mathrm{~cm}$ arasında değişmektedir. Arazide yapılan ilk değerlendirmelerin yanı sıra sondajların çeşitli seviyelerinden laboratuvar analizleri için örnekler alınmıştır. Alınan örnekler içerisinde toplam 834 farklı seviyeye ait 
örneğin hem sedimantolojik analizi hem de paleontolojik incelemeleri ayrıntılı olarak yapılmıştır (Çizelge 1).

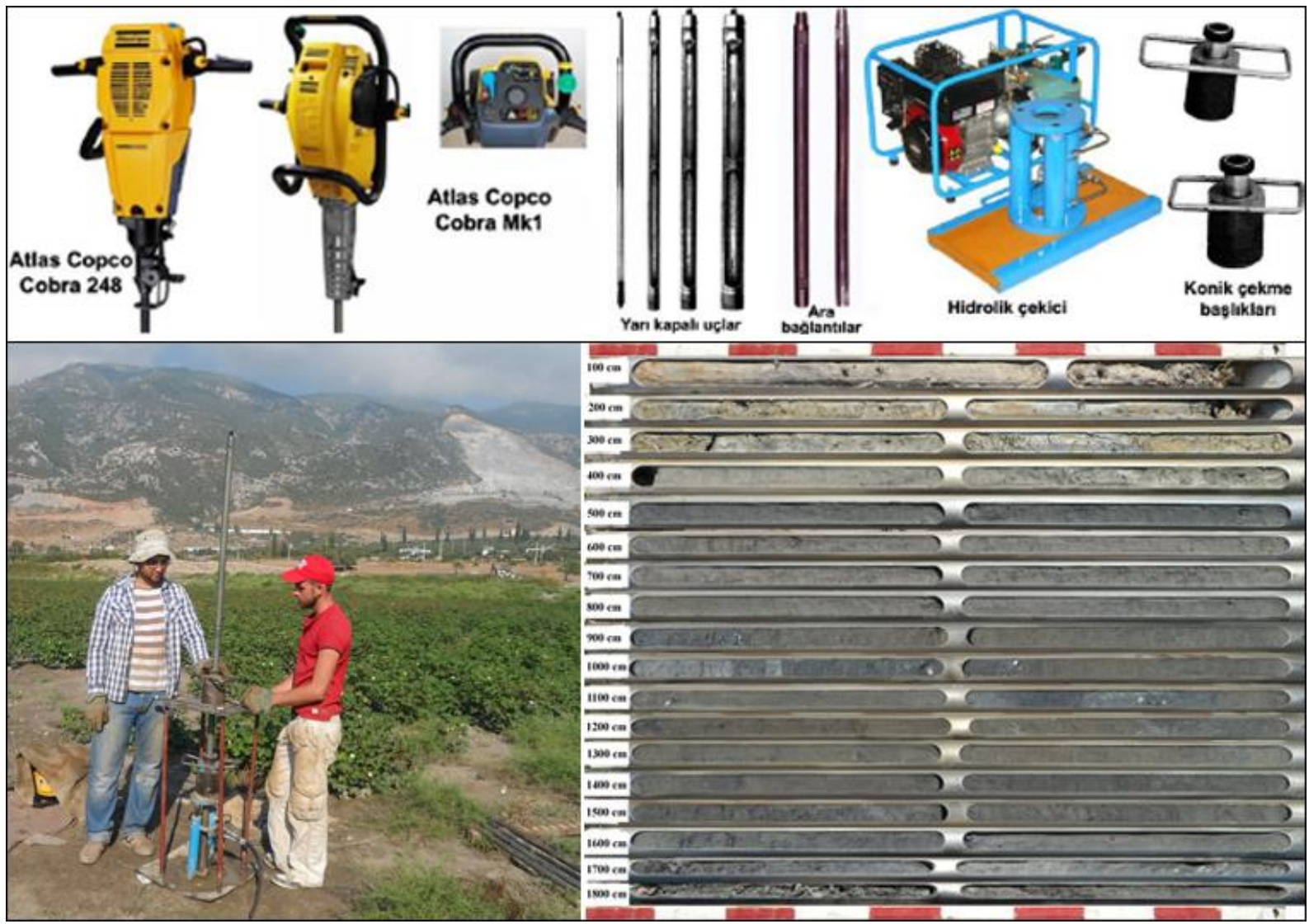

Şekil 2. Benzin motorlu vurma başlıklı Atlas Copco Cobra 248 ve Mk1 ile sondaj ekipmanları, sondaj çalışmalarından bir görünüm ve sondaj karotlarına bir örnek (10 nolu sondaj karotu).

Kaynak: İlhan, 2017.

Sondajlardan alınan örnekler, Ege Üniversitesi Edebiyat Fakültesi Coğrafya Bölümü Alüvyal Jeomorfoloji Laboratuvarı'nda incelenmiştir. Sondajların farklı seviyelerden alınan 5 ve 10 gramlık örnekler bir beher içerisine konulmuş ve içerisine $150 \mathrm{ml}$ su ilave edilerek karıştırılmıştır. Daha sonra örnek içerisine $5 \mathrm{ml}$ (\% 30’luk) hidrojen peroksit konulmuştur. Örnek 1 - 2 gün bekletildikten sonra 230 mesh'lik elekte (Elek gözü 63 mikron) yıkanmıştır. Yıkanan örnekler bir petri içerisine konularak $50 \mathrm{C}^{\circ}$ de kurutulmuştur. Kuruyan örnekler stereo mikroskopta ayrıntılı bir şekilde incelenmiştir. Mikroskopta görülen fosiller sediman örneği içerisinden tek tek seçilmiştir. Ayrılan fosiller foraminiferler, ostrakodlar ve mollusklar (Gastropod ve bivalvia) olarak kendi içlerinde gruplandırılarak ayrı petrilere alınmıştır.

Sediman örneklerinden ayıklanan makro ve mikro fosiller stereo mikroskoba uyumlu bir kamera aracılığı ile hassas bir şekilde ölçekli olarak dijital fotoğrafları çekilmiştir (Şekil 3). Dijital fotoğrafları alınan her bir fosil tanımlanmak ve ortam özellikleri hakkında bilgi edinilmek üzere alanında uzman kişilere gönderilmiştir. Bu çalışmaya konu olan mikropaleontolojik bulgulardan ostrakodların tanımlanmasında Prof. Dr. Atike Nazik, foraminiferlerin tanımlanmasında Prof. Dr. Engin Meriç hocalarımız yardımcı olmuştur. Aynı zamanda çalışma alanı ve yakın çevresinde ostrakod ve 
foraminiferleri içeren çalışmalardaki levha ve şekillerden de yararlanılmıştır (Akbulut ve Öner, 2015; Altınşaçl1, 2014; Aygen, 1996; Cimerman ve Langer, 1991; Çevik, 2009; Gökçen, 1976; Karadaş, 2012; Kayan ve Öner, 2015; Meriç vd., 2004; Müllenhoff vd.,2004; Parlak ve Nazik, 2016; Öner vd., 2013; Öner ve Akbulut, 2015; Tuncer ve Tunoğlu, 2015a; Tuncer ve Tunoğlu, 2015b; Vardar, 2010; Vardar vd., 2017; Vardar ve Öner, 2017; Vardar, 2018; Y1ldı ve Öner, 2015).

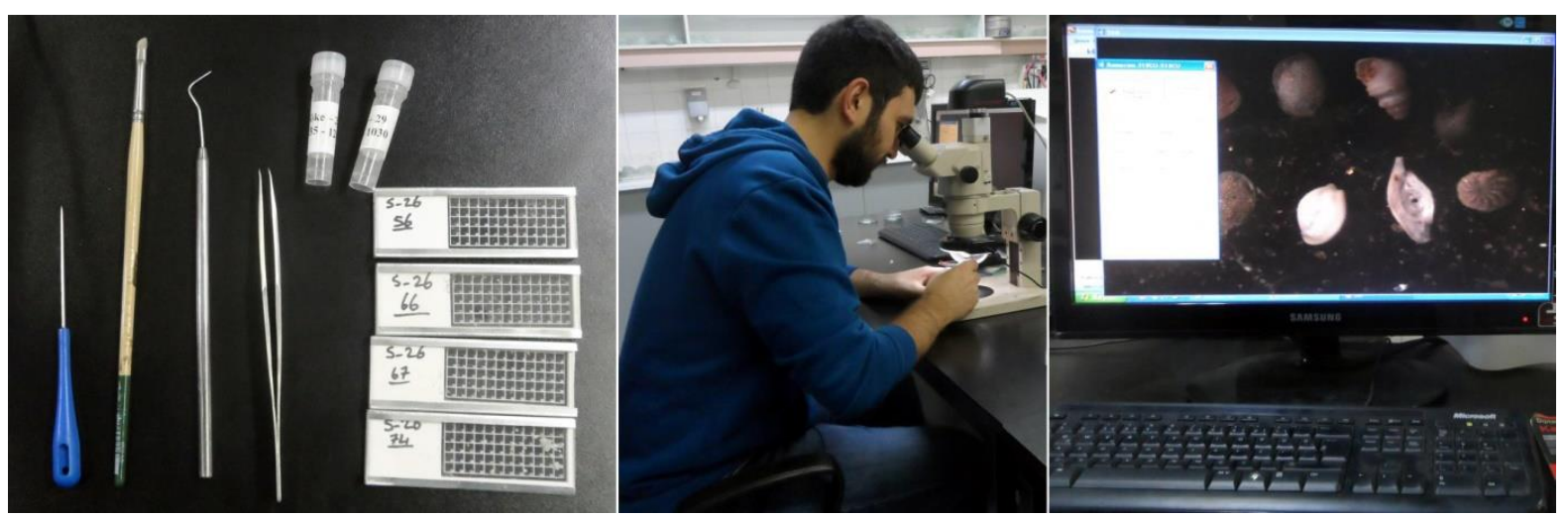

Şekil 3. Sedimanların içindeki fosillerin ayrılmasında, depolanmasında kullanılan araçlar, mikroskop ve fosillerin dijital fotoğraflanmasında kullanılan Kameram yazılımının arayüzü.

Kaynak: İlhan, 2017.

Çizelge 1. Sondaj bilgileri ve örnek sayıları

\begin{tabular}{cccccccc}
\hline $\begin{array}{c}\text { Sondaj } \\
\text { No }\end{array}$ & $\begin{array}{c}\text { Sondaj } \\
\text { Yükseltisi }(\mathrm{m})\end{array}$ & $\begin{array}{c}\text { Sondaj } \\
\text { Derinliği }(\mathrm{cm})\end{array}$ & $\begin{array}{c}\text { İncelenen } \\
\text { Örnek Sayı1 } 1\end{array}$ & $\begin{array}{c}\text { Sondaj } \\
\text { No }\end{array}$ & $\begin{array}{c}\text { Sondaj } \\
\text { Yükseltisi (m) }\end{array}$ & $\begin{array}{c}\text { Sondaj Derinliği } \\
(\mathrm{cm})\end{array}$ & $\begin{array}{c}\text { Incelenen } \\
\text { Örnek Sayı1 }\end{array}$ \\
\hline 1 & 12,5 & 1765 & 26 & 16 & 10,0 & 2000 & 32 \\
\hline 2 & 10,0 & 1500 & 23 & 17 & 4,0 & 500 & 7 \\
\hline 3 & 10,0 & 2300 & 28 & 18 & 3,0 & 875 & 21 \\
\hline 4 & 4,0 & 1700 & 27 & 19 & 1,0 & 1120 & 21 \\
\hline 5 & 5,0 & 1600 & 27 & 20 & 9,0 & 1800 & 26 \\
\hline 6 & 4,0 & 1600 & 27 & 21 & 11,0 & 2000 & 26 \\
\hline 7 & 2,5 & 1700 & 31 & 22 & 17,0 & 1900 & 28 \\
\hline 8 & 5,0 & 1100 & 22 & 23 & 9,0 & 1900 & 33 \\
\hline 9 & 4,0 & 1405 & 27 & 24 & 9,5 & 2000 & 30 \\
\hline 10 & 3,0 & 1800 & 28 & 25 & 13,0 & 1300 & 29 \\
\hline 11 & 9,0 & 2000 & 30 & 26 & 9,0 & 1900 & 81 \\
\hline 12 & 9,0 & 1900 & 28 & 27 & 2,0 & 1800 & 30 \\
\hline 13 & 10,0 & 270 & 7 & 28 & 14,0 & 1900 & 25 \\
\hline 14 & 9,0 & 1700 & 28 & 29 & 9,0 & 1400 & 28 \\
\hline 15 & 8,5 & 1900 & 32 & 30 & 6,0 & 1600 & 26 \\
\hline
\end{tabular}

Kaynak: İlhan, 2017.

\section{Bulgular}

Büyük Menderes Deltası'nın kuzeyinde yapılan alüvyal delgi sondajlardan alınan sediman örnekleri içerisinden toplam 834 farklı seviyeye ait örneğin makro ve mikro fosil incelemeleri yapılmıştır. Bu çalışmada mikro fosil incelemeleri sonucunda bulunan ostrakod ve foraminiferlere yer verilmiştir. 


\subsection{Ostrakodlar}

Ostrakodlar, Arthropoda (Eklem bacaklılar) dalının Crustacea sınıfına ait bir alt sınıf olup, sağ ve sol olarak boyutları birbirinden farklı çift kapak taşıyan, oval, böbrek ya da fasulye şekline sahip mikroskobik organizmalardır (İnan, 2009). Büyük bir çoğunluğu 0,4 mm ile 1,5 mm arasındadır. Bazı tatlı su ostrakodlarının boyutları 5 mm'ye kadar ulaşmaktadır. 30 mm'ye kadar olan makro boyutta olanlarına ise denizel formlarda rastlanılmaktadır (Moore, 1961; Sönmez - Gökçen, 1964).

Ostrakodlar bütün sucul ortamlarda gelişebilmekte ve yaşayabilmektedir. Kaynaklar, yeraltı suları, göller, göletler, akarsular, mevsimlik oluşan göller, denizler, okyanuslar, lagünler, bataklıklar ve haliçler ostrakodların yaşam alanları arasında yer almaktadır (Delorme, 1991). Bu farklı su ortamlarının özelliklerine bağlı olarak (tuzlululuk, sıcaklık, derinlik, suda çözülmüş oksijen, pH, hidrodinamik koşullar vb. özellikler) ostrakodların türleri değişmektedir. Bununla birlikte bulundukları su ortamının özellikleri ecophenotypic farklılıkların oluşmasına neden olmaktadır (Armstrong ve Brasier, 2005; Benson, 1959; Maillet vd., 2013; Reyment vd., 1988; Ruiz vd., 2013). Dolayısiyla ostrakod fosilleri bulundukları ortamı (Tatlı su ortamı, hafif tuzlu su ortamı, denizel ortam) yansitabilmektedirler. Ostrakodların bulundukları ortamı yansıtabilmesi, çevresel değişmelerin belirlenmesinde bir indikatör (Gösterge) olarak kullanılmasını sağlamaktadır (Boomer vd., 2003; Briceag ve Ion, 2013; Frenzel ve Boomer, 2005; Holmes ve Chivas, 2002; Horne vd., 2012; Külköylüoğlu, 2003; Külköylüoğlu, 2004; Sönmez-Gökçen, 1964).

Bu çalışmada bulunan ostrakodlardan yansıttığı ortam özellikleri göz önüne alınarak sediman birimlerinin ayrılmasında ve değişen ortam koşullarının belirlenmesinde yararlanılmıştır (İlhan, 2017). Ostrakodlar tür sayısı ve aynı seviyede birlikte bulunduğu diğer türler de dikkate alındıktan sonra indikatör olarak değerlendirilmiştir. Çünkü bazı ostrakod türleri farklı koşulları tolore edebilme, farklı koşullara uyum sağlama gibi özelliklere sahiptir. Örneğin hafif tuzlu su koşullarını yansıtan tür olan Cyprideis torosa kozmopolit bir dağılıma sahip olup tuzluluğun yanı sıra sıcaklık, oksijen gibi farklı koşullara uyum sağlayabilmektedir (Deckker ve Lord, 2017; Meisch, 2000; Meriç vd., 2003; Roberts vd., 2018). Dolayısıyla Cyprideis torosa bulunduğu seviyelerde ortam koşulları belirlenirken birlikte bulunduğu türlerin özellikleri ile bunların sayısına dikkat edilmiştir (İlhan, 2017).

Acantocythereis hystrix, Argilloecia sp., Aurila arborescens, Aurila convexa, Aurila speyeri, Bacuniella sp., Basslerites berchoni, Callistocythere sp., Candona sp., Candona neglecta, Candona parallela pannonica, Carinocythereis carinata, Cytheretta adriatica, Cytheridea neapolitana, Cytheretta judaea, Carinocythereis carinata, Carinocythereis rhombica, Costa tricostata, Cushmanidea turbida, Cyprideis sp., Cyprideis torosa, Cypridopsis vidua, Cytheretta adriatica, Cytheretta judaea, Cytherois sp., Eucypris sp., Hemicytherura sp., Heterocypris salina, Heterocythereis albomaculata, Hiltermannicythere turbida, Hiltermannicythere rubra, llyocypris sp., Leptocythere sp., Leptocythere bituberculata, Leptocythere multipunctata, Leptocythere ramosa, Limnocythere inopinata, Loxoconcha agilis, Loxoconcha bairdi, Loxoconcha elliptica, Microceratina sp., Paracytherois sp., Paradoxostoma triste, Pseudocandona sp., Pseudocandona compressa, Pontocythere turbida, Semicytherura sp., Semicytherura incongruens, Urocythereis sp., Urocythereis oblonga, Xestoleberis sp., Xestoleberis aurantia ve Xestoleberis depressa incelenen örneklerde bulunan ve tanımlanan ostrakodları oluşturmaktadır (Çizelge 2, Şekil 4, Şekil 5, Şekil 6). 
Çizelge 2. Ostrakodların sondajlara göre dağılımı
Ostracodlar
Sondaj No

\begin{tabular}{|c|c|c|c|c|c|c|c|c|c|c|c|c|c|c|c|c|c|c|c|c|c|c|c|c|c|c|c|c|c|c|c|c|}
\hline \multirow{2}{*}{ Ostracodlar } & \multicolumn{32}{|c|}{ Sondaj No } \\
\hline & 1 & 2 & 3 & 4 & 5 & 6 & 7 & 8 & 9 & 10 & 11 & 12 & 13 & 14 & 415 & 1 & 51 & & 18 & 19 & 20 & 21 & 22 & & & 24 & & 26 & 27 & 28 & 29 & 30 \\
\hline Acantocythereis hystrix & & & & & $\mathrm{X}$ & $\mathrm{X}$ & $\mathrm{X}$ & & & & & & & & & & & & & & & & & & & $\bar{X}$ & & $\mathrm{X}$ & & & & \\
\hline Argilloecia sp. & & & & & $\mathrm{X}$ & $\mathrm{X}$ & $\mathrm{X}$ & $\mathrm{X}$ & & $\mathrm{X}$ & $\mathrm{X}$ & $\mathrm{X}$ & & & & $\mathrm{x}$ & & & $\mathrm{X}$ & & $\mathrm{X}$ & & & $\mathrm{x}$ & $\mathrm{X}$ & $\mathrm{X}$ & & & $\mathrm{X}$ & & & \\
\hline Aurila arborescens & & & & & & & & & & $\mathrm{X}$ & & & & & & & & & & & & & & $\mathrm{x}$ & $x$ & & & & & & & \\
\hline Aurila convexa & & & & $\mathrm{X}$ & & & & & & $\mathrm{X}$ & & & & & & & & & & $\mathrm{X}$ & & & & & & & & & $\mathrm{X}$ & & & \\
\hline Aurila speyeri & & & & & $\mathrm{X}$ & $\mathrm{X}$ & & & & & & & & & & & & & $\mathrm{X}$ & & & & & & & & & & & & & \\
\hline Bacuniella sp. & & & & & $\mathrm{X}$ & & & & & & & & & & & & & & & & & $\mathrm{X}$ & $\mathrm{X}$ & & & & & $\mathrm{X}$ & & & & \\
\hline Basslerites berchoni & & & & $\mathrm{X}$ & & & & & & & $\mathrm{X}$ & $\mathrm{X}$ & & & & & & & & & & & & & & & & & & & & $\mathrm{x}$ \\
\hline Callistocythere sp. & & & & & $\mathrm{X}$ & $\mathrm{X}$ & & & & $\mathrm{x}$ & & & & & & & & & & & $\mathrm{X}$ & & & & & & & & & & & \\
\hline Candona sp. & $\mathrm{X}$ & $\mathrm{X}$ & $\mathrm{X}$ & & & & & & & & & & $\mathrm{X}$ & & $\mathrm{X}$ & & & & & & & & & $\mathrm{x}$ & $\mathrm{x}$ & $\mathrm{X}$ & $\mathrm{x}$ & $\mathrm{X}$ & & $\mathrm{X}$ & & $\mathrm{X}$ \\
\hline Candona neglecta & $\mathrm{X}$ & $\mathrm{X}$ & $\mathrm{X}$ & $\mathrm{X}$ & & & & & & & $\mathrm{X}$ & & $\mathrm{X}$ & $\mathrm{X}$ & & & $X$ & & & $\mathrm{X}$ & $\mathrm{X}$ & $\mathrm{X}$ & & $\mathrm{x}$ & $\mathrm{x}$ & $\mathrm{X}$ & $\mathrm{X}$ & $\mathrm{X}$ & & $\mathrm{X}$ & & \\
\hline Candona parallela pannonica & $\mathrm{X}$ & $\mathrm{X}$ & $\mathrm{X}$ & $\mathrm{X}$ & $\mathrm{X}$ & $\mathrm{X}$ & $\mathrm{X}$ & $\mathrm{X}$ & $\mathrm{X}$ & $\mathrm{X}$ & $\mathrm{X}$ & $\mathrm{X}$ & $\mathrm{X}$ & $\mathrm{X}$ & $\mathrm{x}$ & $\mathrm{x}$ & $x$ & & $\mathrm{X}$ & $\mathrm{X}$ & $\mathrm{X}$ & $\mathrm{X}$ & $\mathrm{X}$ & $\mathrm{x}$ & $\mathrm{X}$ & $\mathrm{X}$ & $\mathrm{X}$ & $\mathrm{X}$ & $\mathrm{X}$ & $\mathrm{X}$ & $\mathrm{X}$ & $\mathrm{x}$ \\
\hline Carinocythereis carinata & & & & & & & & & & $\mathrm{X}$ & & $\mathrm{X}$ & & & & & & & & & & & & & & & & $\mathrm{X}$ & & & & \\
\hline Costa tricostata & & & & & & & & & & & & & & & & & & & & $\mathrm{X}$ & & & & & & & & & & & & \\
\hline Cytheretta adriatica & & & & & & & & & & & & & & & & & & & & & & & & & & & & $\mathrm{X}$ & & & & \\
\hline Cytheridea neapolitana & & & & & & & & & & & $\mathrm{X}$ & & & & & & & & & & & & & & & & & & & & & \\
\hline Cytheretta judaea & & & & & & & & & & & $\mathrm{X}$ & & & & & & & & & & & & & & & & & & & & & \\
\hline Carinocythereis carinata & & & & & & & & & & & & $\mathrm{X}$ & & & & & & & & & & & & & & & & & & & & \\
\hline Carinocythereis rhombica & & & & & & & & & & & & $\mathrm{X}$ & & & & & & & & & & & & & & & & & & & & \\
\hline Cushmanidea turbida & & & & & $\mathrm{X}$ & & $\mathrm{X}$ & & $\mathrm{X}$ & $\mathrm{X}$ & & & & & & & & & & $\mathrm{X}$ & $\mathrm{X}$ & & & & & & & $\mathrm{X}$ & $\mathrm{X}$ & & $\mathrm{X}$ & $\mathrm{X}$ \\
\hline Cyprideis sp. & $\mathrm{X}$ & $\mathrm{X}$ & $\mathrm{X}$ & & & & & & & & & & & & & & & & & & $\mathrm{X}$ & & & & & & & $\mathrm{X}$ & & & & \\
\hline Cyprideis torosa & $\mathrm{X}$ & $\mathrm{X}$ & $\mathrm{X}$ & $\mathrm{X}$ & $\mathrm{X}$ & $\mathrm{X}$ & $\mathrm{X}$ & $\mathrm{X}$ & $\mathrm{X}$ & $\mathrm{X}$ & $\mathrm{X}$ & $\mathrm{X}$ & $\mathrm{X}$ & $\mathrm{X}$ & & $\mathrm{X}$ & $\mathrm{I}$ & & $\mathrm{X}$ & $\mathrm{X}$ & $\mathrm{X}$ & $\mathrm{X}$ & $\mathrm{X}$ & $\mathrm{x}$ & $\mathrm{x}$ & $\mathrm{X}$ & $\mathrm{x}$ & $\mathrm{X}$ & $\mathrm{X}$ & $\mathrm{X}$ & $\mathrm{X}$ & $\mathrm{X}$ \\
\hline Cypridopsis vidua & & & & & & & & & & & $\mathrm{X}$ & & & & & & & & $\mathrm{X}$ & $\mathrm{X}$ & $\mathrm{X}$ & & & & & $\mathrm{X}$ & & & & & & \\
\hline Cytheretta adriatica & & & & & & & $\mathrm{X}$ & & & & & & & & & & & & & & & & & & & & & & & & & \\
\hline \multicolumn{33}{|l|}{ Cytheretta judaea } \\
\hline Cytherois sp. & & & & $\mathrm{X}$ & & & & & & $\mathrm{X}$ & & $\mathrm{X}$ & & & & $\mathrm{x}$ & & & & & $\mathrm{X}$ & & & $\mathrm{x}$ & $x$ & & & & & & & \\
\hline Eucypris sp. & $\mathrm{X}$ & $\mathrm{X}$ & & $\mathrm{X}$ & $\mathrm{X}$ & & $\mathrm{X}$ & & $\mathrm{X}$ & $\mathrm{X}$ & $\mathrm{X}$ & $\mathrm{X}$ & & & & $\mathrm{x}$ & & & $\mathrm{X}$ & $\mathrm{X}$ & $\mathrm{X}$ & & & $\mathrm{x}$ & $\mathrm{x}$ & $\mathrm{x}$ & & & $\mathrm{X}$ & & & $\mathrm{X}$ \\
\hline Hemicytherura $\mathrm{sp}$. & & & & & & & & & & & $\mathrm{X}$ & & & & & & & & & & & & & 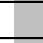 & & & & $\mathrm{X}$ & & & & \\
\hline Heterocypris salina & $\mathrm{X}$ & $\mathrm{X}$ & $\mathrm{X}$ & $\mathrm{X}$ & & & & & & & $\mathrm{X}$ & & & & & & & & & $\mathrm{X}$ & & $\mathrm{X}$ & & $\mathrm{X}$ & $\mathrm{X}$ & & & & $\mathrm{X}$ & & & $\mathrm{X}$ \\
\hline Heterocythereis albomaculata & & & & & & & & & & $\mathrm{X}$ & & & & & & & & & & & & & & & & & & & & & & \\
\hline Hiltermannicythere turbida & & & & & & & & & & & & $\mathrm{X}$ & & & & & & & & $\mathrm{x}$ & & & & & & & & $\mathrm{X}$ & $\mathrm{X}$ & & $\mathrm{X}$ & \\
\hline Hiltermannicythere rubra & & & & & & & & & & & & $\mathrm{X}$ & & & & & & & & $\mathrm{X}$ & & & & & & & & & & & & \\
\hline Ilyocypris sp. & $\mathrm{X}$ & $\mathrm{X}$ & $\mathrm{X}$ & $\mathrm{X}$ & $\mathrm{X}$ & $\mathrm{X}$ & $\mathrm{X}$ & $\mathrm{X}$ & $\mathrm{X}$ & $\mathrm{X}$ & $\mathrm{X}$ & $\mathrm{X}$ & $\mathrm{X}$ & $\mathrm{X}$ & $\mathrm{x}$ & $\mathrm{X}$ & $\mathrm{I}$ & & $\mathrm{X}$ & $\mathrm{X}$ & $\mathrm{X}$ & $\mathrm{X}$ & $\mathrm{X}$ & $\mathrm{x}$ & $\mathrm{x}$ & $\mathrm{X}$ & $\mathrm{x}$ & $\mathrm{X}$ & $\mathrm{X}$ & $\mathrm{X}$ & $\mathrm{X}$ & $\mathrm{X}$ \\
\hline Leptocythere sp. & & & $\mathrm{X}$ & $\mathrm{X}$ & $\mathrm{X}$ & & & & & & & $\mathrm{X}$ & & & $\mathrm{X}$ & $\mathrm{X}$ & & & & & $\mathrm{X}$ & & $\mathrm{X}$ & & & & & $\mathrm{X}$ & $\mathrm{X}$ & & $\mathrm{X}$ & \\
\hline Leptocythere bituberculata & & & & & & & $\mathrm{X}$ & & & & $\mathrm{X}$ & $\mathrm{X}$ & & & & $x$ & & & & & $\mathrm{X}$ & & & & & $\mathrm{x}$ & & & 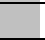 & & & $\mathrm{X}$ \\
\hline Leptocythere multipunctata & & & & & & & & & & & & & & & & & & & & & & & & $\mathrm{x}$ & $\mathrm{X}$ & & & & $\mathrm{X}$ & & & \\
\hline Leptocythere ramosa & & & & & & & & & & & $\mathrm{X}$ & $\mathrm{X}$ & & & & $\mathrm{x}$ & & & & & & & & & & & & $\mathrm{X}$ & & & & \\
\hline Limnocythere inopinata & & & & & & & & & & & & & & & & & & & $\mathrm{X}$ & & & & & & & & & & & & & \\
\hline Loxoconcha agilis & & & & $\mathrm{X}$ & & & & & & $\mathrm{X}$ & $\mathrm{X}$ & $\mathrm{X}$ & $\mathrm{X}$ & & & & & & & & $\mathrm{X}$ & & & & & $\mathrm{X}$ & & & & & & $\mathrm{X}$ \\
\hline Loxoconcha bairdi & & & $\mathrm{X}$ & & & & & & & & & $\mathrm{X}$ & & & & & & & & & & & & & & $\mathrm{X}$ & & $\mathrm{X}$ & & & & \\
\hline Loxoconcha elliptica & & & $\mathrm{X}$ & $\mathrm{X}$ & $\mathrm{X}$ & & $\mathrm{X}$ & $\mathrm{X}$ & & $\mathrm{X}$ & $\mathrm{X}$ & $\mathrm{X}$ & $\mathrm{X}$ & & $\mathrm{X}$ & $\mathrm{x}$ & & & $\mathrm{X}$ & & $\mathrm{X}$ & $\mathrm{X}$ & $\mathrm{X}$ & $\mathrm{x}$ & $\mathrm{X}$ & $\mathrm{X}$ & & $\mathrm{X}$ & $\mathrm{X}$ & & $\mathrm{X}$ & $\mathrm{X}$ \\
\hline Microceratina $\mathrm{sp}$. & & & & & & & & & & & & & & & & & & & $\mathrm{X}$ & & & & & & & & & & 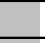 & & & \\
\hline Paracytherois sp. & & & & & & & & & & & $\mathrm{X}$ & $\mathrm{X}$ & & & & $x$ & & & & & & & & & & $\mathrm{x}$ & & & $\mathrm{X}$ & & & \\
\hline \multicolumn{33}{|l|}{ Paradoxostoma triste } \\
\hline Pseudocandona sp. & $\mathrm{X}$ & $\mathrm{X}$ & $\mathrm{X}$ & & $\mathrm{X}$ & & & $\mathrm{X}$ & & $\mathrm{X}$ & $\mathrm{X}$ & $\mathrm{X}$ & & $\mathrm{X}$ & & & & & $\mathrm{X}$ & & $\mathrm{X}$ & & & & $\mathrm{X}$ & $\mathrm{X}$ & $\mathrm{x}$ & & & & & $\mathrm{X}$ \\
\hline \multicolumn{33}{|l|}{ Pseudocandona compressa } \\
\hline Pontocythere turbida & & & & & & & & & & & $\mathrm{X}$ & & & & & & & & & & & & & & & & & & & & & \\
\hline Semicytherura sp. & & & & & & & $\mathrm{X}$ & & & & & $\mathrm{X}$ & & & & & & & $\mathrm{X}$ & & $\mathrm{X}$ & & & & & $\mathrm{X}$ & & $\mathrm{X}$ & $\mathrm{X}$ & & & \\
\hline Semicytherura incongruens & & & & & & & & & & $\mathrm{X}$ & & $\mathrm{X}$ & & & & $\mathrm{x}$ & & & $\mathrm{X}$ & & & & & & & & & $\mathrm{X}$ & & & & \\
\hline Urocythereis sp. & & & & & & & & & & $\mathrm{x}$ & & & & & & & & & & & & & & & & & & & & & & \\
\hline Urocythereis oblonga & & & & & & & $\mathrm{X}$ & & & & & & & & & & & & & & & & & & & & & & & & & \\
\hline Xestoleberis $\mathrm{sp}$. & & & $\mathrm{X}$ & & & & & & & & $\mathrm{X}$ & $\mathrm{X}$ & & $\mathrm{X}$ & & & & & $\mathrm{X}$ & & & & & $\mathrm{x}$ & $\mathrm{x}$ & $\mathrm{X}$ & & & $\mathrm{X}$ & & & \\
\hline Xestoleberis aurantia & & & & & & & & & & & $\mathrm{X}$ & $\mathrm{X}$ & & & & & & & & & & & & & & $\mathrm{X}$ & & & & & & \\
\hline Xestoleberis depressa & & & & & & & & & & & $\mathrm{X}$ & & & & & & & & & & & & & & & & & & & & & \\
\hline
\end{tabular}

Kaynak: İlhan, 2017. 
Sondajların hepsinde farklı türlere ait ostrakodlara rastlanılmıştır. Bununla birlikte sondajlarda bulunan ostrakodların tür çeşitliği ve yoğunluğunda sondajlara göre farklılıklar da söz konusudur. Argilloecia sp., Candona sp., Candona neglecta, Candona parallela pannonica, Cyprideis torosa, Eucypris sp., Heterocypris salina, llyocypris sp., Leptocythere sp., Loxoconcha elliptica, Pseudocandona sp. tüm sondajların hemen hemen hepsinde bulunan baskın ostrakodlar olarak belirlenmiştir (Çizelge 2). Cyprideis torosa bu türler içerisinde sayı bakımından en fazla bulunan tür olmuştur.

Candona sp., Candona neglecta, Candona parallela pannonica, Cypridopsis vidua, llyocypris sp., Pseudocandona sp., Pseudocandona compressa flüvyal - kolüvyal sedimanların ayrılmasında yararlanılan ostrakodlardır. Genellikle tatlı su koşullarında yaşayan bu türler incelenen örnekler içerisinde yüzey ile günümüz deniz seviyesi arasındaki seviyelerde baskın türler olarak bulunmuştur (Altınsacl1, 2014; Aygen, 1996; İlhan, 2017; Külköylüoglu, 2003; http://www.marinespecies.org, 2018).

Bacuniella sp., Cyprideis sp., Cyprideis torosa, Cytherois sp., Eucypris sp., Hemicytherura sp., Heterocypris salina, Limnocythere inopinata, Loxoconcha elliptica gibi türler denizel sedimanlar ile flüvyal sedimanlar arasında geçiş özelliği gösteren birim içerisinde sayı bakımından baskındır (Altınsaçl1, 2014; Aygen, 1996; Boomer and Frenzel, 2011; Frenzel and Boomer, 2005; İlhan, 2017; Perçin-Paçal ve ark., 2015; http://www.marinespecies.org, 2018).

Acantocythereis hystrix, Argilloecia sp., Aurila arborescens, Aurila convexa, Aurila speyeri, Basslerites berchoni, Callistocythere sp., Carinocythereis carinata, Costa tricostata, Cytheretta adriatica, Cytheridea neapolitana, Cytheretta judaea, Carinocythereis carinata, Carinocythereis rhombica, Cushmanidea turbida, Heterocythereis albomaculata, Hiltermannicythere turbida, Hiltermannicythere rubra, Leptocythere sp., Leptocythere bituberculata, Leptocythere multipunctata, Leptocythere ramosa, Loxoconcha agilis, Loxoconcha bairdi, Microceratina sp., Paracytherois sp., Paradoxostoma triste, Pontocythere turbida, Semicytherura sp., Semicytherura incongruens, Urocythereis sp., Urocythereis oblonga, Xestoleberis sp., Xestoleberis aurantia ve Xestoleberis depressa denizel sedimanların ayrılmasında yararlanılan sığ denizel ortamı yansıtan ostrakodlardandır. Tuzlu su, hafif tuzlu su koşullarını yansıtan bu türler incelenen örnekler içerisinde günümüz deniz seviyesinin altında bulunmuştur (Altınsacl1, 2014; Aygen, 1996; İlhan, 2017; Perçin-Paçal ve ark., 2015; http://www.marinespecies.org, 2018). 


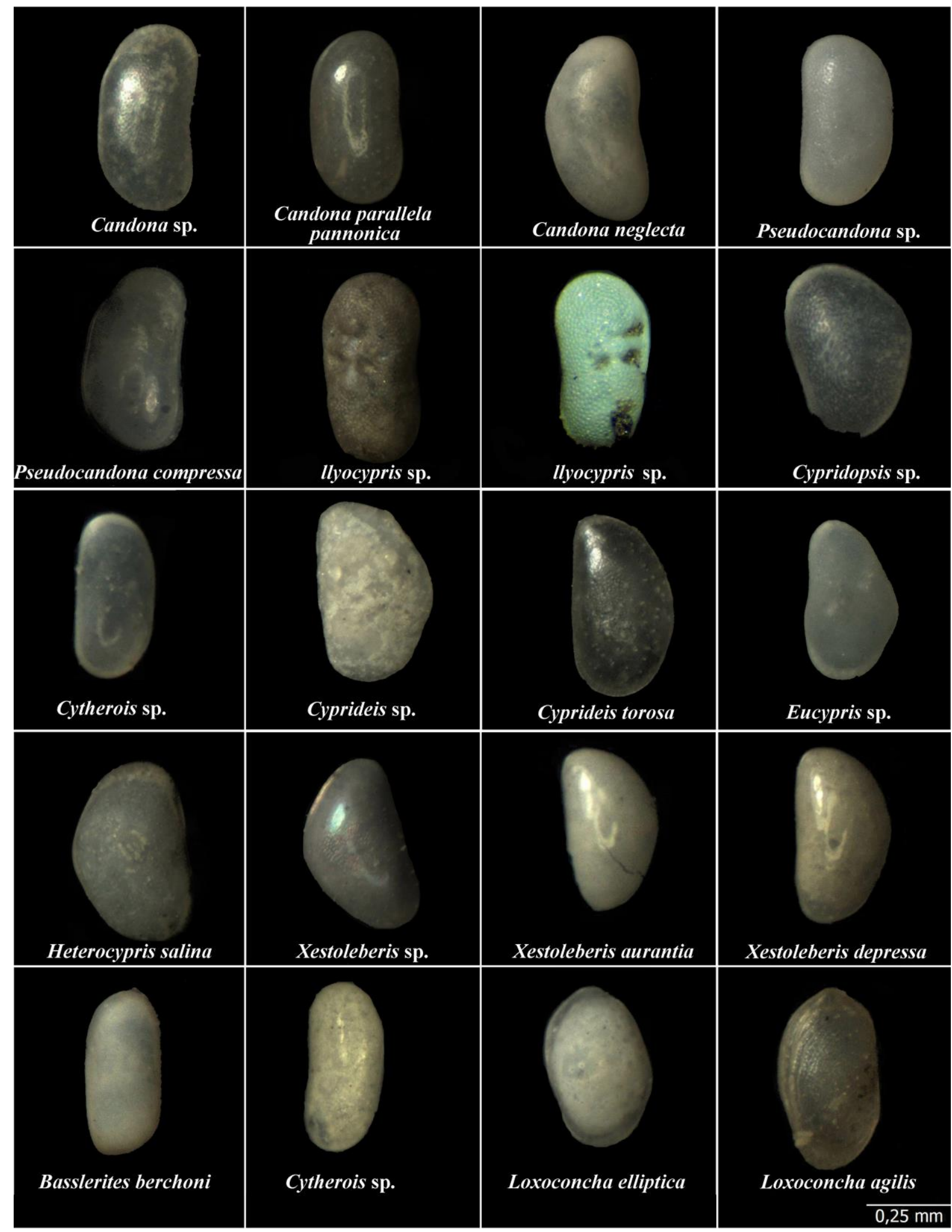

Şekil 4. Sondajlarda bulunan ostrakod fosilleri.

Kaynak: İlhan, 2017. 


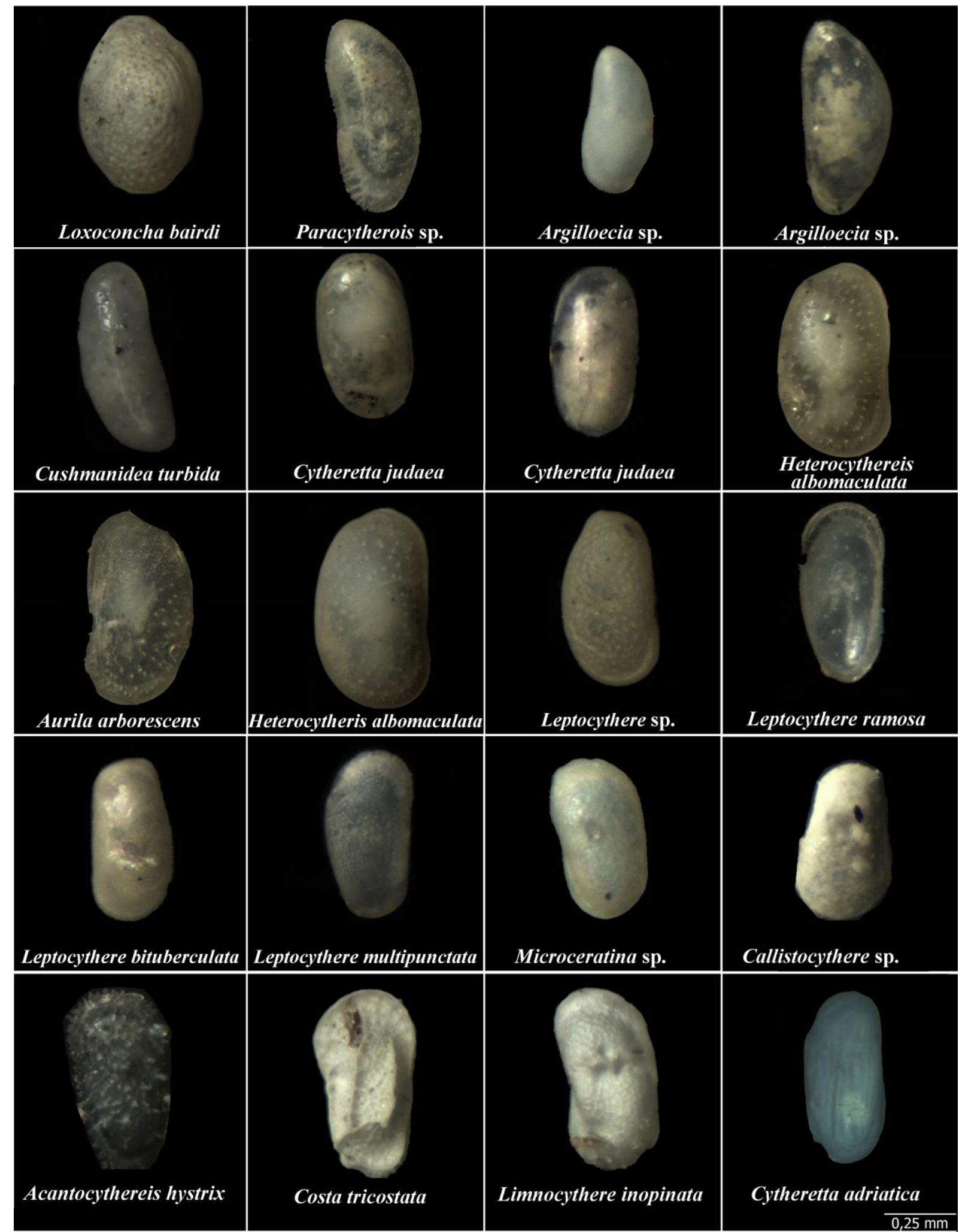

Şekil 5. Sondajlarda bulunan ostrakod fosilleri.

Kaynak: İlhan, 2017. 


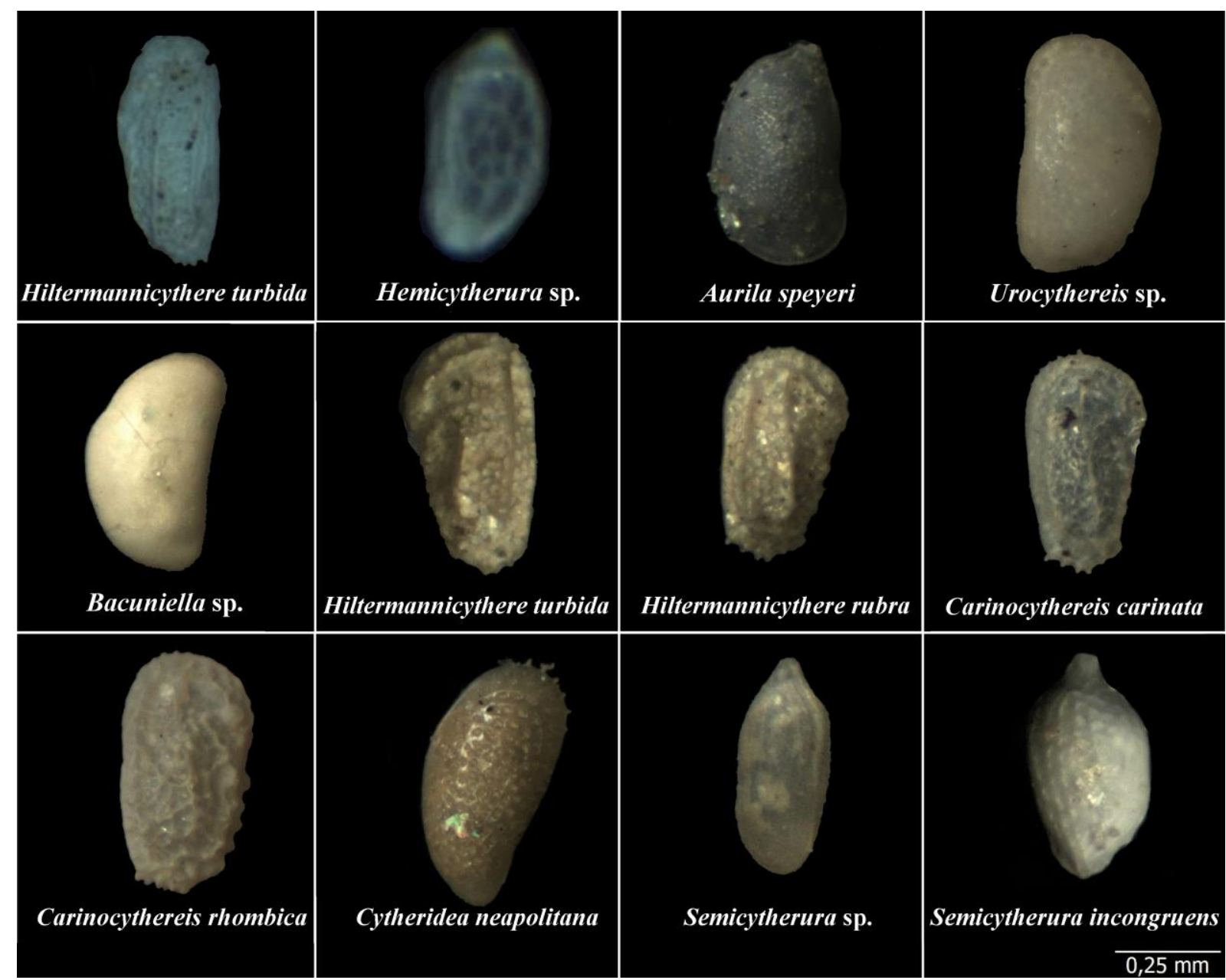

Şekil 6. Sondajlarda bulunan ostrakod fosilleri.

Kaynak: İlhan, 2017.

\subsection{Foraminiferler}

Mikrofosillerin en önemli takımı olan ve mikropaleontolojinin ana konusunu oluşturan foraminiferler, yeryuvarı üzerinde hayatın belirmesiyle ortaya çıkmış ve zamanla gelişmeye başlamış olan bir hücreli ve genellikle çok küçük olan canlılardır (İnan, 2009; Meriç, 1983). Foraminiferlerin büyük bir çoğunluğu denizel ortamlarda yaşamaktadır. Bunun yanında tatlı ve hafif tuzlu sularda da yaşayanları bulunmaktadır. Farklı derinliklerdeki yaşam şartlarına uyum sağlayabilen foraminiferler, özellikle neritik bölgede yaşamlarını sürdürürler (Meriç, 1983).

Farklı denizel ortamlarda bulunmaları ve genellikle çok sayıda olmalarından dolayı foraminiferler çevresel koşulları incelemek için kullanılan en uygun organizma grubu olarak değerlendirilmektedir. Foraminiferlerin yaşamları çökelme ortamının derinlik, sıcaklık, tuzluluk, deniz dibi morfolojisi, oksijen, organik madde miktarı ve ışık koşulları gibi bazı ekolojik faktörlere bağlıdır (İnan, 2009). Dolayısıyla foraminiferlerin bu faktörlere bağlılıkları ekolojik ve çevresel koşullarda meydana gelen değişmelerin belirlenmesine, değerlendirilmesine olanak sağlamaktadır (Alve, 1995; Murray, 1991; Phleger, 1970; Yanko ve ark., 1999). 
Çalışmada mikropaleontolojik bulgular arasında yer alan foraminiferlere ait farklı türler bulunmuştur. Bulunan foraminiferler incelenen örnekler içerisinde günümüz deniz seviyesi ve altındaki seviyelerde sayı ve çeşitlilik açısından oldukça zengindir (Çizelge 3).

Çizelge 3. Foraminiferlerin sondajlara göre dağılımı.

\begin{tabular}{|c|c|c|c|c|c|c|c|c|c|c|c|c|c|c|c|c|c|c|c|c|c|c|c|c|c|c|c|c|c|c|}
\hline \multirow{2}{*}{ Foraminiferler } & \multicolumn{30}{|c|}{ Sondaj No } \\
\hline & 1 & 2 & 3 & 4 & 5 & 6 & 7 & 8 & 9 & 10 & 11 & 12 & 13 & 14 & 15 & 16 & 17 & 18 & 19 & 20 & 21 & 22 & 23 & 24 & 25 & 262 & 272 & 282 & 29 & 30 \\
\hline Adelosina $\mathrm{sp}$. & & & $\mathrm{X}$ & & & $\mathrm{X}$ & $\mathrm{X}$ & & & $\mathrm{X}$ & $\mathrm{x}$ & & & & & $\mathrm{X}$ & & $\mathrm{X}$ & & $\mathrm{X}$ & $\mathrm{x}$ & & & $\mathrm{X}$ & & $\mathrm{x}$ & & & $\mathrm{X}$ & $\bar{x}$ \\
\hline Adelosina cliarensis & & & & & & & & & & $\mathrm{X}$ & $\mathrm{x}$ & & & & & & & & & & & & & & & $\mathrm{X}$ & & & & $\mathrm{x}$ \\
\hline Adelosina duthiersi & & & & & & & & & & & & & & & & & & & & & & & & & & $\mathrm{X}$ & & & & \\
\hline Adelosina mediterranensis & & & & & & & & & & & & & & & $\mathrm{X}$ & $\mathrm{X}$ & & & & & & & & $\mathrm{x}$ & & $\mathrm{X}$ & & & & \\
\hline Ammonia sp. & & & $\mathrm{x}$ & $\mathrm{X}$ & & & $\mathrm{X}$ & & & $\mathrm{X}$ & & & $\mathrm{x}$ & & & $\mathrm{x}$ & $\mathrm{x}$ & & & & $\mathrm{x}$ & & & & & $\mathrm{X}$ & & & & $\mathrm{x}$ \\
\hline Ammonia compacta & & & & $\mathrm{X}$ & $\mathrm{x}$ & $\mathrm{X}$ & $\mathrm{X}$ & $\mathrm{X}$ & $\mathrm{X}$ & $\mathrm{X}$ & $\mathrm{X}$ & $\mathrm{X}$ & & $\mathrm{X}$ & $\mathrm{x}$ & $\mathrm{x}$ & & & $\mathrm{X}$ & & & & & & & $\mathrm{x}$ & $\mathrm{X}$ & & $\mathrm{X}$ & $\bar{x}$ \\
\hline Ammonia tepida & $\mathrm{X}$ & $\mathrm{X}$ & $\mathrm{x}$ & $\mathrm{X}$ & $\mathrm{X}$ & $\mathrm{X}$ & $\mathrm{X}$ & $\mathrm{X}$ & $\mathrm{x}$ & $\mathrm{X}$ & $\mathrm{x}$ & $\mathrm{X}$ & & $\mathrm{X}$ & $\mathrm{x}$ & $\mathrm{x}$ & & $\mathrm{X}$ & $\mathrm{x}$ & $\mathrm{X}$ & & & $\mathrm{x}$ & $\mathrm{x}$ & & $\mathrm{x}$ & $\mathrm{X}$ & & $x$ & $\mathrm{x}$ \\
\hline Brizalina sp. & & & & & & & & & & & $\mathrm{x}$ & & & & & & & & & & & & & & & & & & & \\
\hline Challengerella bradyi & & & & & & & & & & & & & & $\mathrm{X}$ & & & & & & & & & & & & & & & & \\
\hline Cribroelphidium sp. & & & $x$ & & & & & & & $\mathrm{X}$ & $\mathrm{x}$ & & & & & & & & & & & & & & & & & & & \\
\hline Elphidium sp. & & $\mathrm{X}$ & & $\mathrm{X}$ & & $\mathrm{x}$ & $\mathrm{x}$ & $\mathrm{x}$ & $\mathrm{x}$ & $\mathrm{X}$ & $\mathrm{x}$ & $\mathrm{x}$ & & & $\mathrm{x}$ & $\mathrm{x}$ & & $\mathrm{X}$ & $\mathrm{x}$ & $\mathrm{x}$ & & & $\mathrm{x}$ & $\mathrm{X}$ & & $\mathrm{x}$ & $\mathrm{X}$ & & $\mathrm{X}$ & $\mathrm{x}$ \\
\hline Elphidium advenum & & & & & & & & & & & $\mathrm{x}$ & & & & & & & & & & & & & & & & & & & $\mathrm{x}$ \\
\hline Elphidium complanatum & & & $\mathrm{X}$ & $\mathrm{X}$ & & $\mathrm{X}$ & $x$ & & $\mathrm{X}$ & $\mathrm{X}$ & $\mathrm{x}$ & $\mathrm{X}$ & & & $\mathrm{x}$ & $\mathrm{x}$ & & & $\mathrm{X}$ & & & & $\mathrm{x}$ & $\mathrm{X}$ & & $\mathrm{X}$ & & & $\mathrm{x}$ & $\bar{x}$ \\
\hline Elphidium crispum & & $\mathrm{X}$ & & & & $\mathrm{X}$ & $\mathrm{x}$ & $\mathrm{X}$ & $\mathrm{x}$ & $\mathrm{X}$ & $\mathrm{x}$ & $\mathrm{x}$ & & & $\mathrm{x}$ & $\mathrm{x}$ & & & $\mathrm{x}$ & & & & & & & $\mathrm{x}$ & $\mathrm{X}$ & & & $\mathrm{x}$ \\
\hline Elphidium macellum & & & & & & & $\mathrm{X}$ & & & & & & & & & & & & & & & & & & & $\mathrm{X}$ & & & & \\
\hline Globigerina sp. & & & & & & $\mathrm{X}$ & & & & $\mathrm{X}$ & $\mathrm{x}$ & & & & & & & & $\mathrm{X}$ & & & & & & & & & & & \\
\hline Lobatula lobatula & & & & & $\mathrm{X}$ & $\mathrm{X}$ & $\mathrm{x}$ & & $\mathrm{x}$ & $\mathrm{X}$ & $\mathrm{x}$ & $\mathrm{X}$ & & & & $\mathrm{x}$ & & & & $\mathrm{X}$ & & & & $\mathrm{X}$ & & $\mathrm{X}$ & $\mathrm{X}$ & & $x$ & \\
\hline \multicolumn{31}{|l|}{ Neoponides sp. } \\
\hline Neoponides bradyi & & & & & & & $\mathrm{X}$ & & $\mathrm{x}$ & $\mathrm{X}$ & & & & & & $\mathrm{x}$ & & & & $\mathrm{X}$ & & & & $\mathrm{x}$ & & $\mathrm{x}$ & $\mathrm{X}$ & & & $\mathrm{x}$ \\
\hline Nonion sp. & & & $x$ & $\mathrm{X}$ & $\mathrm{X}$ & & & $\mathrm{X}$ & $\mathrm{X}$ & $\mathrm{X}$ & $\mathrm{x}$ & $\mathrm{x}$ & & & $\mathrm{x}$ & $\mathrm{x}$ & & & & $\mathrm{X}$ & & & & $\mathrm{x}$ & & $\mathrm{x}$ & & & $x$ & $\bar{x}$ \\
\hline Nonion depressulum & & & $\mathrm{X}$ & & $\mathrm{X}$ & & & & & $\mathrm{X}$ & $\mathrm{x}$ & $\mathrm{x}$ & & & $\mathrm{x}$ & $\mathrm{x}$ & & & & $\mathrm{x}$ & & & & $\mathrm{x}$ & & $\mathrm{X}$ & & & & \\
\hline Orbulina sp. & & & & & & $\mathrm{x}$ & & & & $\mathrm{X}$ & & & & & & & & & & & & & & & & & & & & \\
\hline Ouinqueloculina sp. & & $\mathrm{x}$ & & $\mathrm{X}$ & & $\mathrm{x}$ & $\mathrm{x}$ & $\mathrm{X}$ & & $\mathrm{X}$ & $\mathrm{x}$ & $\mathrm{x}$ & $\mathrm{x}$ & $\mathrm{X}$ & $\mathrm{x}$ & $\mathrm{x}$ & $\mathrm{x}$ & & & $\mathrm{x}$ & $\mathrm{x}$ & & & $\mathrm{x}$ & & $x$ & $\mathrm{X}$ & & $\mathrm{X}$ & $\mathrm{x}$ \\
\hline Ouinqueloculina seminula & & $\mathrm{X}$ & $\mathrm{x}$ & $\mathrm{X}$ & $\mathrm{X}$ & $\mathrm{x}$ & $\mathrm{X}$ & & & $\mathrm{X}$ & $\mathrm{x}$ & $\mathrm{x}$ & $\mathrm{x}$ & $\mathrm{X}$ & $\mathrm{x}$ & $\mathrm{x}$ & & & & & & & & $\mathrm{X}$ & & $\mathrm{x}$ & $\mathrm{X}$ & & $\mathrm{x}$ & $\mathrm{x}$ \\
\hline Planorbulina mediterranensis & & & & & & & $\mathrm{x}$ & & & & & & & & & & & & & & & & & & & $\mathrm{x}$ & & & & $\mathrm{x}$ \\
\hline Rosalina bradyi & & & & & & & $\mathrm{x}$ & & & $\mathrm{X}$ & & $\mathrm{X}$ & & $\mathrm{X}$ & & $\mathrm{x}$ & & & & & & & & & & $\mathrm{X}$ & & & & \\
\hline Siphotextularia concava & & & & & & & & & & & $\mathrm{x}$ & & & & & & & & & & & & & & & & & & & \\
\hline Spiroloculina sp. & & & & & & & $\mathrm{x}$ & & & $\mathrm{X}$ & & & & & & & & & & & & & & & & $\mathrm{x}$ & & & & \\
\hline Spiroloculina angulosa & & & & & & & $\mathrm{X}$ & & & $\mathrm{X}$ & & & & & & & & & & & & & & & & $\mathrm{X}$ & & & & \\
\hline Textularia sp. & & & & & & & $\mathrm{x}$ & & & & $\mathrm{x}$ & $\mathrm{x}$ & & & & & & & & & & & & $\mathrm{x}$ & & & & & & \\
\hline Triloculina sp. & & & & & $\mathrm{X}$ & $\mathrm{x}$ & $\mathrm{X}$ & & & $\mathrm{X}$ & $\mathrm{x}$ & $\mathrm{X}$ & & & & $\mathrm{x}$ & & & & & & & & & & $\mathrm{X}$ & & & & \\
\hline Triloculina marioni & & & & & $\mathrm{X}$ & $\mathrm{x}$ & $\mathrm{X}$ & & & $\mathrm{X}$ & $\mathrm{x}$ & $\mathrm{X}$ & & & & $\mathrm{x}$ & & & & & & & & & & & & & & \\
\hline
\end{tabular}

Kaynak: İlhan, 2017.

Adelosina sp., Adelosina cliarensis, Adelosina duthiersi, Adelosina mediterranensis, Ammonia sp., Ammonia compacta, Ammonia tepida, Brizalina sp., Challengerella bradyi, Cribroelphidium sp., Elphidium sp., Elphidium advenum, Elphidium complanatum, Elphidium crispum, Elphidium macellum, Globigerina sp., Lobatula lobatula, Neoponides sp., Neoponides bradyi, Nonion sp., Nonion depressulum, Orbulina sp., Ouinqueloculina sp., Ouinqueloculina seminula, Planorbulina mediterranensis, Rosalina bradyi, Spiroloculina sp., Spiroloculina angulosa, Textularia sp., Triloculina sp., Triloculina marioni incelenen seviyelerde bulunan foraminiferlerdir (Çizelge 3; Şekil 7; Şekil 8). 
Bulunan foraminiferler içerisinde Ammonia tepida 17, 22, 25, 28 nolu sondajlar dışındaki tüm sondajlarda bulunan ve baskın olan foraminiferdir (Çizelge 3). Ammonia tepida dışında Ammonia compacta, Elphidium complanatum, Elphidium crispum, Lobatula lobatula, Ouinqueloculina seminula incelenen örnekler içerisinde en fazla bulunan foraminiferlerdendir (Çizelge 3; Şekil 7; Şekil 8). 22, 25 ve 28 nolu sondajlarda ise foraminiferlere ait herhangi bir türe rastlanılmamıştır. Bu sondajların farklı seviyelerinde bulunan ostrakod türleri de tatlı su koşullarını yansıtan türler oluşmaktadır (Çizelge 2). Dolayısıyla 22, 25 ve 28 nolu sondajlarda bulunan ostrakod türleri, foraminiferlere ait herhangi bir türün bulunamaması ve sedimantolojik analiz sonuçlarına göre bu noktalarda inilen derinlik itibarıly denizel bir ortamın olmadığ söylenebilir.

İncelenen örnekler içerisinde bulunan foraminiferler sı̆̆ denizel ortamı yansıtan türlerden oluşmaktadır (İlhan, 2017; Kayan ve Öner; 2015; Meriç vd., 2000; Meriç vd., 2004; Meriç ve Yokeş, 2008; Nazik, 1994; Öner ve Akbulut, 2015; Vardar, 2018). Bununla birlikte pelajik - plankton özellikteki foraminiferlerden olan Orbulina sp. ve Globigerina sp. 6, 10, 11 ve 19 nolu sondajların günümüz deniz seviyesi; altındaki derinliklerinde bulunmuştur. $\mathrm{Bu}$ foraminiferler bulundukları seviyelerde sı̆̆ denizel ortamı yansıtan foraminiferler ve ostrakodlar ile birlikte olup, sayısal olarak oldukça azdır. Açık denizel ortamı karakterize eden bu türlerin yüzeylerinin aşınmış ve kristalleşmiş olması bulundukları bu sondaj noktalarına taşınmış olduklarını göstermektedir (Akbulut ve Öner, 2015; İlhan, 2017; Meriç vd., 2004; Şekil 8). 


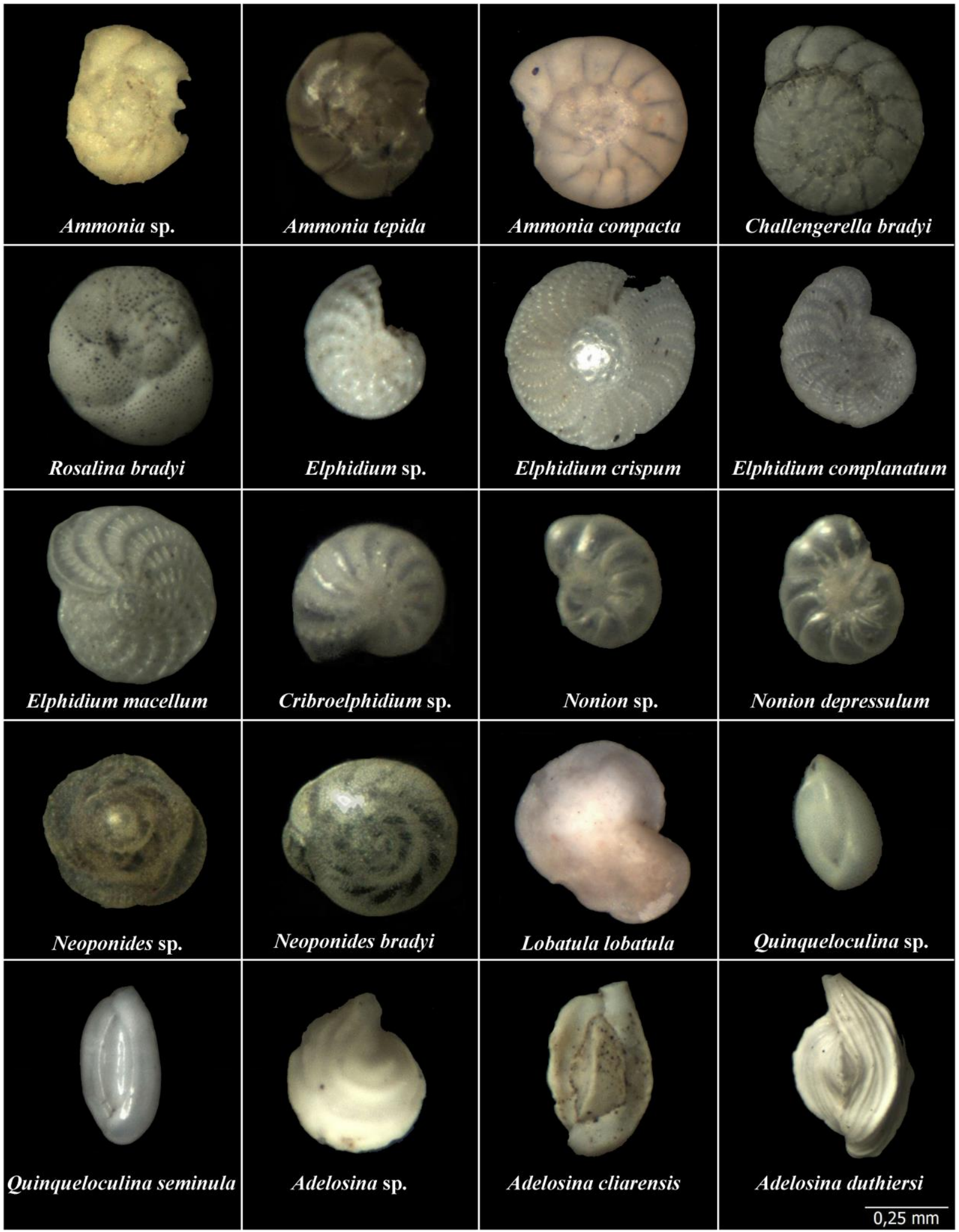

Şekil 7: Sondajlarda bulunan foraminifer fosilleri.

Kaynak: İlhan, 2017. 

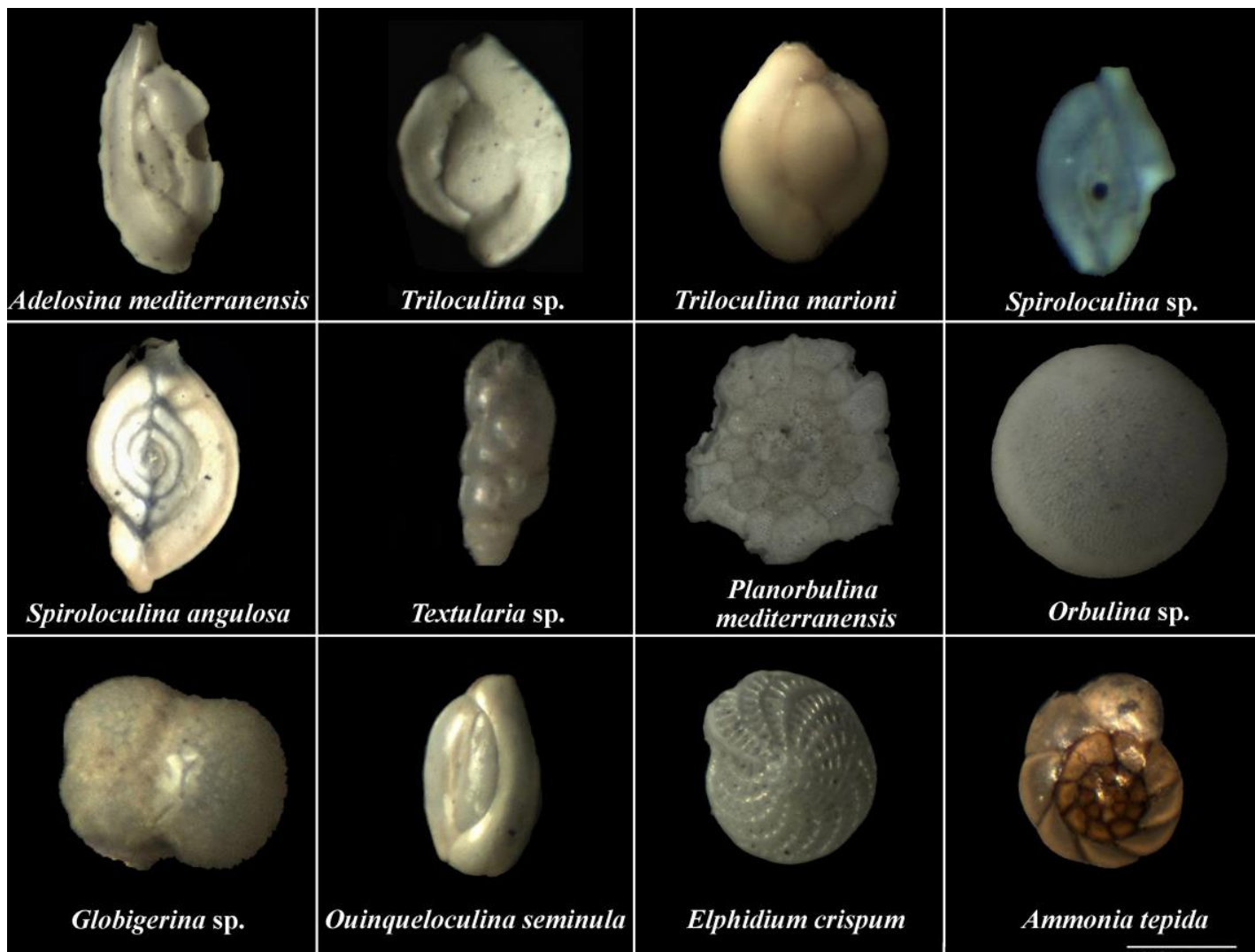

Triloculina marioni

Spiroloculina sp.

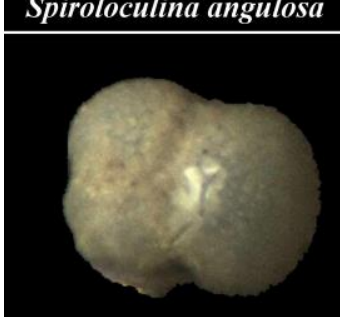

Globigerina sp.
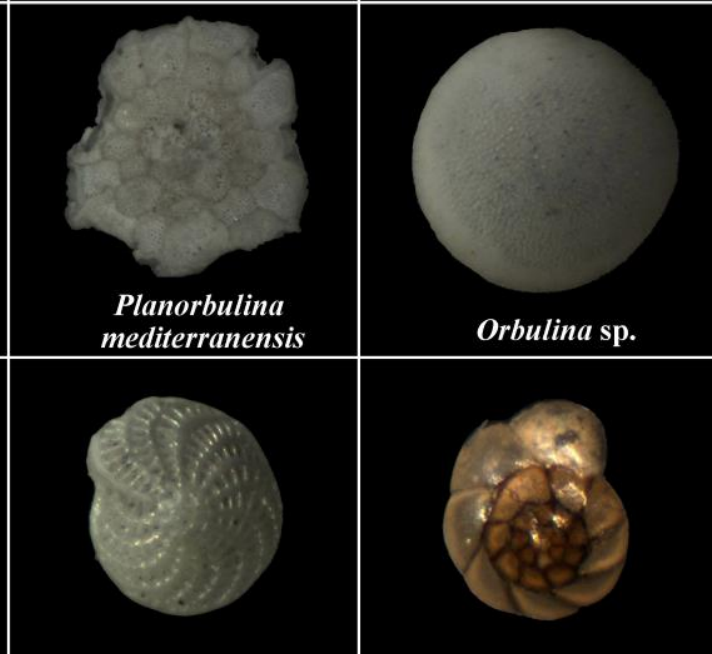

Elphidium crispum

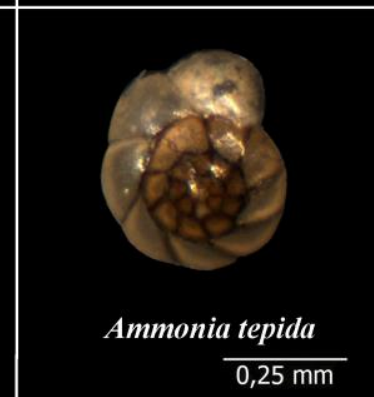

Şekil 8: Sondajlarda bulunan foraminifer fosilleri.

Kaynak: İlhan, 2017.

\section{Sonuç}

Çalışmada Büyük Menderes Deltası'nın kuzeyinde 30 farklı noktada yapılan alüvyal delgi sondajdan alınan sediman örnekleri içerisinde 834 farklı seviyede bulunan ostrakod ve foraminiferlere ait mikropaleontolojik bulgular sunulmuştur. Farklı ortamları (Hafif tuzlu su, denizel, tatlı su, bataklık, lagün gibi) yansıtan ostrakod ve foraminiferler tanımlanmıştır (Çizelge 2, Çizelge 3).

Alüvyal delgi sondajları ile alınan sediman örneklerindeki değişimler belirlenmiş, değişen doğal ortamın göstergesi olarak mikropaleontolojik bulgulardan yararlanılmıştır. Yapılan diğer analizler ve mikropaleontolojik bulgular ile sedimanlar üç ana birime ayrılmıştır. Flüvyal - kolüvyal, geçiş ve denizel sedimanlar ayrılan ana birimlerdir (İlhan, 2017). Bu birimlerin ayrılmasinda, ortam özelliklerinin belirlenmesinde mikropaleontolojik bulgulardan indikatör (Gösterge) olarak yararlanılmıştır. Mikropaleontolojik bulguların indikatör olarak değerlendirilmesinde; türlerin sayısı, ostrakod ve foraminiferlere ait türlerin varlığı veya yokluğu, birlikte bulunduğu türler ile ilişkileri göz önünde bulundurulmuştur. Elde edilen sonuçlar sediman birimlerinin ayrılmasında, değişen ortam koşullarının belirlenmesinde mikropaleontolojik bulguların oldukça güvenilir veriler sağladığını göstermiştir.

\section{Teşekkür ve Bilgilendirme}

Sediman örnekleri içerisinde bulduğumuz ostrakodların tanımlanmasındaki yardımlarından dolayı Prof. Dr. Atike Nazik hocamıza ve foraminiferlerin tanımlanmasındaki yardımlarından dolayı Prof. Dr. Engin Meriç hocamıza teşekkür ederiz. 
To cite: İlhan, R., Öner, E. (2019). Micropaleontological Findings in Core Drillings in the Northern part of the Büyük Menderes Delta, Coğrafi Bilimler Dergisi/ Turkish Journal of Geographical Sciences, 17(2), 345-366, doi: 10.33688/ aucbd.558247

$\begin{array}{ccc}\text { Cografi Bilimler Dergisi } & \text { Corrafi } \\ \text { Bilimler } \\ \text { Dergisi }\end{array}$

\title{
Micropaleontological Findings in Core Drillings in the Northern part of the Büyük Menderes Delta
}

\author{
Rifat İlhan*a, Ertuğ Öner ${ }^{b}$
}

\section{EXTENDED ABSTRACT}

\section{Introduction}

Nowadays, micropaleontological data is mainly used to determine the changes occurring in the natural environment. This fact is related to the reflections of the living environment. Every living thing lives in an environment with different characteristics i.e. terrestrial, marine, lagoon, swamp, lake, brackish water, fresh water etc. and therefore, fossils can be identified according to their environment, leading to the retrospective evaluations. Microfossils, which are better preserved in sediments and are present in abundance, provide very reliable information about their respective environments (Barbieri and Vaiani, 2018; Boomer et al., 2003; Murray, 2000; Murray, 2006). In this regard, fossils of living things remaining in their natural living environments are of vast importance such as in the case of benthic foraminifera.

There are many reports published using micropaleontological data, most of which are related to the deltas and coastal areas. Micropaleontological data reflects the changes in environmental characteristics in deltas and coasts, where the natural environment tends to change faster. Therefore, scientists have used micropaleontological data for this type of studies (Akbulut and Öner, 2015; Armstrong and Brasier, 2005; Gökçen, 1976; İlhan, 2017; Karadaş, 2014; Kayan, 2015; Kayan and Öner, 2015; Müllenhoff et al., 2004; Öner et al., 2013; Öner and Akbulut, 2015; Öner, 2016; Öner et al., 2018; Vardar, 2010; Vardar and Öner, 2017; Vardar et al., 2017; Vardar, 2018; Y1ldı and Öner, 2015).

In this study focusing of the development of the alluvial cones in the southern slopes of the Mount Samsun located to the north of the Büyük Menderes Delta in Holocene and associate it with the physical geographical characteristics of the basins that form the cones, 30 alluvial core drilling were utilized. Sedimentological and paleontological analyzes were performed and the sediment properties of the samples, taken from the core drilling studies, were examined in detail. Sediments have been divided into three main units: fluvial, transition and marine. Paleontological data were used as indicators to separate these units. Herein, this study aims to report the micropaleontological findings that were used as an indicator to determine changing ambient conditions and the separation of sediment units.

\section{Material and Method}

Sediment samples have been taken from alluvial core drilling points at the intersection of alluvial cones and plain surface in the south of Samsun Mountain. These cones of different sizes are called Söke, Akçakonak (Gümelez), Güllübahçe, Boynak, Atburgazı, Tuzburgazı, Doğanbey and Dalyan alluvial cones. Alluvial core drillings made at different points in different periods were numbered as 01, 02, 03.

\footnotetext{
*Corresponding Author: Rifat İlhan, rifatcografya@gmail.com

${ }^{a}$ Adiyaman University, Faculty of Arts and Science, Department of Geography, Adıyaman, Turkey, http://orcid.org/0000-00018392-9349

${ }^{\mathrm{b} E g e}$ University, Faculty of Letters, Department of Geography, İzmir, Turkey, http://orcid.org/0000-0002-9712-5277
} 
The drilling points indicated by the $\mathrm{K}$ drilling number refer to the drilling carried out around Kadıkalesi within the scope of paleogeography - geoarchaeology (Figure 1).

The drillings have been carried out using different equipment belonging to the Geography Department of Ege University. Most of the drillings carried out in different periods have descended below the sea level. The depths of the drillings from the surface ranges $270-2300 \mathrm{~cm}$. In addition to the initial assessments in the field, samples from various levels of the drillings were taken for laboratory analysis. Both sedimentological and paleontological investigations of 834 samples from different levels were carried out in detail.

The obtained samples were examined in the Alluvial Geomorphology Laboratory located in the Geography Department of Ege University. Samples of 5 and 10 grams were transferred into a beaker having $150 \mathrm{ml}$ water. Then $5 \mathrm{ml}(30 \%)$ of hydrogen peroxide was poured into the sample. The sample was allowed to stand for 1-2 days and then washed through a 230-mesh sieve (63-micron mesh). The washed samples were placed in a petri dish and dried at $50{ }^{\circ} \mathrm{C}$. The dried samples were examined in detail under a stereo microscope. The fossils seen under the microscope were selected individually from the sediment sample. The fossils separated were grouped as foraminifera, ostracods and mollusca and taken into separate petri dishes.

Macro and micro fossils, extracted from the sediment samples, were taken in a precise scale and digital photographs were taken by a stereo microscope compatible camera. The digital photographs of each fossil were taken and sent to experts in the field to identify and to know the characteristics of the environment. Prof. Atike Nazik helped in the identification of ostracods from the micropaleontological findings while Prof. Engin Meriç in the identification of foraminifers. At the same time, plates and shapes in the works including ostracod and foraminifera were used in the study area and its immediate surroundings (Akbulut and Öner, 2015; Altınşaçl1, 2014; Aygen, 1996; Çevik, 2009; Cimerman and Langer, 1991; Çevik, 2009; Gökçen, 1976; Karadaş, 2012; Kayan and Öner, 2015; Meriç et al., 2004; Müllenhoff et al., 2004; Öner et al., 2013; Öner and Akbulut, 2015; Parlak and Nazik, 2016; Tuncer and Tunoğlu, 2015a; Tuncer and Tunoğlu, 2015b; Vardar, 2010; Vardar and Öner, 2017; Vardar et al., 2017; Vardar, 2018; Y1ldız and Öner, 2015).

\section{Findings}

\subsection{Ostracods}

Ostracods can develop and live in all aquatic environments and such as springs, groundwater, lakes, ponds, streams, seasonal lakes, seas, oceans, lagoons, swamps and estuaries are all among its habitats (Delorme, 1991). The types of ostracods vary depending on the characteristics of these different aquatic environments (salinity, temperature, depth, dissolved oxygen in water, $\mathrm{pH}$, hydrodynamic conditions etc.,). However, the characteristics of the water environment, in which they are present, lead to ecophenotypic differences (Armstrong and Brasier, 2005; Benson, 1959; Maillet et al., 2013; Reyment et al., 1988; Ruiz et al., 2013). Therefore, ostracod fossils may reflect the type of environment they are located in. The ability of the ostracods to reflect their environment allows it to be used as an indicator to determine the environmental (Boomer et al., 2003; Briceag and Ion, 2013; Frenzel and Boomer, 2005; Holmes and Chivas, 2002; Horne et al., 2012; Külköylüoğlu, 2003; Külköylüoğlu, 2004; Sönmez-Gökçen, 1964).

In this study, the ostracods have been used to separate sediment units and to determine the changing ambient conditions by considering the reflected environmental characteristics (Illhan, 2017). Ostracods have been considered as indicator after taking into account the number of species and other species with which they coexist at the same level. Some ostracod species have different features such as the ability to tolerate and adapt to different conditions. For example, Cyprideis torosa, which can be found in brackish water, has a cosmopolitan distribution that enables it to adapt to different conditions such as temperature, oxygen and salinity (Deckker and Lord, 2017; Meisch, 2000; Meriç et al., 2003; Roberts et al., 2018). Therefore, when determining the environmental conditions at the levels where 
Cyprideis torosa is found, its characteristics and the number of these species have been taken into consideration (Illhan, 2017).

Acantocythereis hystrix, Argilloecia sp., Aurila arborescens, Aurila convexa, Aurila speyeri, Bacuniella sp., Basslerites berchoni, Callistocythere sp., Candona sp., Candona neglecta, Candona parallela pannonica, Carinocythereis carinata, Cytheretta adriatica, Cytheridea neapolitana, Cytheretta judaea, Carinocythereis carinata, Carinocythereis rhombica, Costa tricostata, Cushmanidea turbida, Cyprideis sp., Cyprideis torosa, Cypridopsis vidua, Cytheretta adriatica, Cytheretta judaea, Cytherois sp., Eucypris sp., Hemicytherura sp., Heterocypris salina, Heterocythereis albomaculata, Hiltermannicythere turbida, Hiltermannicythere rubra, llyocypris sp., Leptocythere sp., Leptocythere bituberculata, Leptocythere multipunctata, Leptocythere ramosa, Limnocythere inopinata, Loxoconcha agilis, Loxoconcha bairdi, Loxoconcha elliptica, Microceratina sp., Paracytherois sp., Paradoxostoma triste, Pseudocandona sp., Pseudocandona compressa, Pontocythere turbida, Semicytherura sp., Semicytherura incongruens, Urocythereis sp., Urocythereis oblonga, Xestoleberis sp., Xestoleberis aurantia and Xestoleberis depressa constitute the ostracods found and identified in the samples examined.

Candona sp., Candona neglecta, Candona parallela pannonica, Cypridopsis vidua, llyocypris sp., and Pseudocandona compressa are ostracods used in the separation of fluvial - colluvial sediments. These species, which generally live in fresh-water, were dominant species at the level between surface and at the present sea level (Altınsacl1, 2014; Aygen, 1996; İlhan, 2017; Külköylüoglu, 2003; http://www.marinespecies.org, 2018).

Species such as Bacuniella sp., Cyprideis sp., Cyprideis torosa, Cytherois sp., Eucypris sp., Hemicytherura sp., Heterocypris salina, Limnocythere inopinata, and Loxoconcha elliptica are dominant in number in the unit showing the transition between marine and fluvial sediments (Altınsaçl1, 2014; Aygen, 1996; Boomer and Frenzel, 2011; Frenzel and Boomer, 2005; İlhan, 2017; Perçin-Paçal et al., 2015; http://www.marinespecies.org, 2018).

Acantocythereis hystrix, Argilloecia sp., Aurila arborescens, Aurila convexa, Aurila speyeri, Basslerites berchoni, Callistocythere sp., Carinocythereis carinata, Costa tricostata, Cytheretta adriatica, Cytheridea neapolitana, Cytheretta judaea, Carinocythereis carinata, Carinocythereis rhombica, Cushmanidea turbida, Heterocythereis albomaculata, Hiltermannicythere turbida, Hiltermannicythere rubra, Leptocythere sp., Leptocythere bituberculata, Leptocythere multipunctata, Leptocythere ramosa, Loxoconcha agilis, Loxoconcha bairdi, Microceratina sp., Paracytherois sp., Paradoxostoma triste, Pontocythere turbida, Semicytherura sp., Semicytherura incongruens, Urocythereis sp., Urocythereis oblonga, Xestoleberis sp., Xestoleberis aurantia, and Xestoleberis depressa are among the ostracods reflecting the shallow marine environment used to separate marine sediments. These species, which reflect saltwater and brackish water conditions, were found below the present sea level (Altınsacl1, 2014; Aygen, 1996; İlhan, 2017; Perçin-Paçal et al., 2015; http://www.marinespecies.org, 2018).

\subsection{Foraminifera}

Foraminifera are considered to be the most suitable group of organisms used to study environmental conditions; as they are present in different marine environments and are often numerous. The life of the foraminifera depends on some ecological factors such as depth, temperature, salinity, seabed morphology, oxygen, amount of organic matter and light conditions (İnan, 2009). Therefore, the dependence of foraminifers on these factors allows to determine and evaluate the changes in ecological and environmental conditions (Alve, 1995; Murray, 1991; Phleger, 1970; Yanko et al., 1999).

Adelosina sp., Adelosina cliarensis, Adelosina duthiersi, Adelosina mediterranensis, Ammonia sp., Ammonia compacta, Ammonia tepida, Brizalina sp., Challengerella bradyi, Cribroelphidium sp., Elphidium sp., Elphidium advenum, Elphidium complanatum, Elphidium crispum, Elphidium macellum, 
Globigerina sp., Lobatula lobatula, Neoponides sp., Neoponides bradyi, Nonion sp., Nonion depressulum, Orbulina sp., Ouinqueloculina sp., Ouinqueloculina seminula, Planorbulina mediterranensis, Rosalina bradyi, Spiroloculina sp., Spiroloculina angulosa, Textularia sp., Triloculina sp., and Triloculina marioni are foraminifera found at the studied levels.

Among the foraminifera found, Ammonia tepida is the predominant foraminifera found in all drillings except for 17, 22, 25, and 28. Additionally, Ammonia compacta, Elphidium crispum, Elphidium complanatum, Lobatula lobatula, and Quinqueloculina seminula were the most common foraminifera among the samples examined. No foraminifera species were found in the drilling samples 22, 25 and 28. Ostracod species found at different levels of these drillings also consist of species living in freshwater conditions.

\section{Results}

In this study, micropaleontological findings of ostracods and foraminifera of 834 different samples obtained at different levels have been presented. The sediment samples were taken from alluvial core drilling in 30 different points north of Büyük Menderes Delta. Ostracods and foraminifera reflecting different environments were identified.

Changes in sediment samples taken with the alluvial core drillings were determined and micropaleontological findings were used as indicators of the changing natural environment. Sediments are divided into three main units with other analyzes and micropaleontological findings. Fluvial colluvial, transition and marine sediments are the main units separated (Illhan, 2017). In the separation of these units, micropaleontological findings were used as indicators in the determination of environmental properties. In the evaluation of micropaleontological findings as indicators; the number of species, the presence or absence of ostracod and foraminifera species and their relationship with the species were considered. According to the results obtained, micropaleontological findings provide very reliable data to separate sediment units and to determine changing environmental conditions.

\section{Referanslar/References}

Akbulut, H., Öner, E. (2015). Antik Patara Kentinde Paleocoğrafya ve Jeoarkeoloji Araştırmalarına Paleontolojik Analizlerin Katkıs1. B. Takmer, E. N. Akdoğu Arca, N. G. Özdil (Ed.), Vir doctus Anatolicus Studies in Memory of Sencer Şahin $/$ Sencer Şahin Anısına Yazılar içinde (33-59), İstanbul: Kuzgun Yayınevi.

Alve, E. (1995). Benthic Foraminifera Responses to Estuarine Pollution: A Review. Journal of Foraminiferal Research 25, 190-203.

Altınsaçl1, S. (2014). Species Diversity and Distribution of Ostracoda (Crustacea) in Mesosaline Lake Bafa (Aegean Region, Turkey). Journal of Entomology and Zoology Studies, 2 (2), 16-32.

Armstrong, H.A., Brasier, M.D. (2005). Microfossils. Oxford: Blackwell Publishing.

Aygen, C. (1996). İzmir İli ve Civarının Ostracoda (Crustacea) Faunası. Ege Üniversitesi, Fen Bilimleri Enstitüsü, Yayımlanmamış Yüksek Lisans Tezi, İzmir.

Barbieri, G., Vaiani, S.C. (2018). Benthic Foraminifera or Ostracoda? Comparing the Accuracy of Palaeoenvironmental Indicators from a Pleistocene Lagoon of the Romagna Coastal Plain (Italy). Journal of Micropaleontology, 37, 203230.

Benson, R.H. (1959). Ecology of Recent Ostracodes of the Todos Santos Bay Region, Baja California, Mexico. Kansas University Paleontological Contributions.

Briceag, A., Ion, G. (2014). Holocene Ostracod and Foraminiferal Assemblages of the Romanian Black Sea Shelf. Quaternary International 345, 119-129.

Boomer, I., Horne, D., Slipper, I. (2003). The Use of Ostracods in Palaeoenvironmental Studies, or What can you do with an Ostracod Shell?. Paleontological Society Paper, 9, 153-179.

Boomer, I., Frenzel, P. (2011). Possible Environmental and Biological Controls on Carapace Size in Cyprideis torosa (Jones, 1850). Joannea Geological of Paleontology, 11, 26-27.

Cimerman, F., Langer, M.R. (1991). Mediterranean Foraminifera. Ljubljana: Slovenska Akademija Znanosti. 
Çevik, M. G. (2009). Büyük Menderes Nehri Önü (Dip Burnu-Tekeağaç Burnu Arası) Kıta Sahanlı̆̆ının Güncel Sedimanlarında Bulunan Bentik Foraminiferlerin Taksonomik ve Otoekolojik Incelemesi. Çukurova Üniversitesi, Fen Bilimleri Enstitüsü, Yayımlanmamış Yüksek Lisans Tezi, Adana.

Deckker, P.D., Lord, A. (2017). Cyprideis torosa: A Model Organism for the Ostracoda?. Journal of Micropalaeontology, 36 (1), 3-6.

Delorme, L.D. (1991). Ostracoda. J. H. Thorpe, A. P. Covich (Ed.), Ecology and Classification of North American Invertebrates (811-848). New York: Academic Press.

Erdoğan, K. (1993). Paleontolojik Sınıflandırma ve Adlandırma Terimleri. Jeoloji Mühendisliği Dergisi, 43, 121-124.

Frenzel, P., Boomer, I. (2005). The Use of Ostracods from Marginal Marine, Brackish Waters as Bioindicators of Modern and Quaternary Environmental Change. Paleogeography, Paleoclimatology, Paleoecology, 225, 68-92

Gökçen, N. (1976). A Paleontological and Paleoecological Investigation of the Post-Glacial Marda Çayı Deposits in the NorthEastern Coasts of the Aegean Sea. Bulletin de la Societe Geologique de France, 7 (18), 469-279.

Holmes, J. H., Chivas, A. R., (2002). The Ostracoda: Applications in Quaternary Research. Geophysical Monography, 131, 536.

Horne, D. J., Holmes, J., Rodriguez-Lazaro, J., Viehberg, F. A. (Ed.) (2012). Ostracoda as Proxies for Quaternary Climate Changes. Elsevier Science

İlhan, R. (2017). Samsun Dă̆ı Fiziki Coğrafya Özelliklerinin Etek - Alüvyal Jeomorfolojisi Üzerine Etkisi. Ege Üniversitesi, Sosyal Bilimler Enstitüsü, Yayımlanmamış Doktora Tezi, İzmir.

İlhan, R., Öner, V. (2018). Sedimantolojik ve Paleontolojik Analizler ile Güllübahçe (Söke/Aydın) Birikinti Konisinin Gelişimi: Ön Sonuçlar. Sosyal Bilimler Dergisi, 31, 471-478.

İnan, N. (2009). Paleontoloji (Fosil Bilimi). Ankara: Seçkin Yayıncılık.

Karadaş, A. (2012). Bornova Ovası ve Çevresinin Fiziki Coğrafyası. Ege Üniversitesi, Sosyal Bilimler Enstitüsü, Yayımlanmamış Doktora Tezi, İzmir.

Karadaş, A. (2014). Bornova Ovası (İzmir) Holosen Paleocoğrafyası ve Kıyı Çizgisi Değişmeleri, Ege Coğrafya Dergisi, 23 (2), 37-52.

Kayan, İ. (2015). Küçük Menderes Delta Ovasında (Selçuk) Derbent Vadisinin Jeomorfolojik Özellikleri ve Çukuriçi Höyüğü. C. Şimşek, B. Duman, E. Konakçı (Ed.), Mustafa Büyükkoloancı'ya Armağan içinde (369-380), İstanbul: Ege Yayınları.

Kayan, İ. Öner, E. (2015). Sedimantolojik ve Paleontolojik Verilerle Gediz Delta Ovasında (İzmir) Alüvyal Jeomorfoloji Araştırmaları. Ege Coğrafya Dergisi, 24 (2), 1-27.

Külköylüoğlu, O. (2003). Ecology of Freshwater Ostracoda (Crustacea) from Lakes and Reservoirs in Bolu, Turkey. Journal of Freshwater Ecology, 18, 343-347.

Külköylüoğlu, O. (2004). On the Usage of Ostracods (Crustacea) as Bioindicator Species in Different Aquatic Habitats in the Bolu Region, Turkey. Ecological Indicator Journal, 4, 139-147.

Maillet, S., Milhau, B., Vreulx, M., Danelian, T., Monnet, T., Nicollin, J.P. ( 2013). Ecophenotypic Variation of the Devonian Benthic Ostracod Species Cavellina Rhenana Krömmelbein 1954: A Paleoenvironmental Proxy for the Ardenne (France-Belgium) and Rheno-Hercynian Realm. Palaeogeography, Palaeoclimatology, Palaeoecology 392, 324-334.

Meisch, C. (2000). Freshwater Ostracoda of Western and Central Europe. Berlin: Spektrum Akademischer Verlag.

Meriç, E. (1983). Foraminiferler. Ankara: MTA Yayınları Eğitim Serisi 26.

Meriç, E., Kerey, E., Tunoğlu, C., Avşar, N., Önal, B.Ç. (2000). Yeşilçay (Ağva-KD İstanbul) Yöresi Geç Kuvaterner İstiflerinin Mikrofaunast ve Sedimantolojisi. Türkiye Jeoloji Bülteni, 43 (2), 83-98.

Meriç, E., Kerey, E., Avşar, N., Tuğrul, A. B., Suner, F., Sayar, A. (2003). Haliç (İstanbul) Kıyı Alanlarında (UnkapanıAzapkap1) Gözlenen Holosen Çökelleri Hakkında Yeni Bulgular. Hacettepe Üniversitesi Yerbilimlerim Uygulama ve Araştırma Merkezi Bülteni 28, 9-32.

Meriç, E., Avşar, N., Bergin, F. (Ed.) 2004. Benthic Foraminifera of Eastern Aegean Sea (Turkey) Systematics and Autoecology. İstanbul: Turkish Marine Research Foundation.

Meriç, E., Yokeş, M.B. (2008). Recent Benthic Foraminifera along the Southwest Coasts of Antalya (SW Turkey) and the Impact of Alien Species on Authochtonous Fauna. Micropaleontology, 54 (3-4), 185-186. 
Moore, R. C. (1961). Treatise on Invertebrate Paleontology. Part Q Arthropoda 3. Crustacea Ostracoda. Geological Society of America and University of Kansas Press.

Murray, J.W. (1991). Ecology and Palaeoecology of Benthic Foraminifera. New York: Longman Scientific and Technical.

Murray, J.W. (2000). When Does Environmental Variability Become Environmental Change? The Proxy Record of Benthic Formanifera. Environmental Micropaleontology, 15, 7-37.

Murray, J.W., (2006). Ecology and Applications of Benthic Foraminifera. Cambridge: Cambridge University Press.

Müllenhoff, M., Handl, M., Knipping, M., Brückner, H. (2004). The Evolution of Lake Bafa (Western Turkey) Sedimentological, Microfaunal and Palynological Results. Geographie der Meereund Küsten Coastline Reports 1: 5566.

Nazik, A. (1994). İskenderun Körfezi Holosen Ostrakodlar1. Maden Tetkik ve Arama Dergisi, 116: 15-20.

Öner, E., Meriç, E., Nazik, A., Avşar, N. (2013). Yeni Bademli Höyüğü Çevresinde Alüvyal Jeomorfoloji ve Paleontoloji Calışmaları (Gökçeada - Çanakkale). E. Öner (Ed.) Prof. Dr. İlhan Kayan'a Armağan içinde (839-871) İzmir: Ege Üniversitesi Yayınları Edebiyat Fakültesi Yayın No: 181.

Öner, E., Akbulut, H. (2015). Paleocoğrafik - Jeoarkeolojik Bulgular Işığında Patara Apollon Tapınağının Yerinin Tartışılması: Patara Apollon Tapınağı Kısık Boğazında Mıydı? (Eşen Ovası - Muğla/Antalya). Ege Coğrafya Dergisi, 24 (2), 69105.

Öner, E. (2016). Ege ve Akdeniz Kıyılarımızda Paleocoğrafya ve Jeoarkeoloji Araştırmaları. Ege Coğrafya Dergisi, 25 (1), 51 66.

Öner, E., Vardar, S., Karadaş, A., İlhan, R. (2018). Bornova Ovası ile Bayraklı Höyüğü Çevresinde Paleocoğrafya ve Jeoarkeoloji Araştırmaları (İzmir). TÜCAUM 30. Yıl Uluslararası Coğrafya Sempozyumu Bildiri Kitabı. 296-312, Ankara.

Parlak, D., Nazik, A. (2016). Ostracods of the Mediterranean (The Gulf Of Antalya) and the Aegean Sea (Ayvalik and Kuşadas1) and Their Biogeographical Distributions. Bulletin of the Mineral Research and Exploration 152, 63-83.

Perçin-Paçal, F., Altınsaçlı, S., Balkıs, H. (2015). An Updated Checklist of Recent Marine and Coastal Brackish Water Ostracods (Crustacea Ostracoda) in Turkey. Journal of Entomology and Zoology Studies, 3 (3), 20-33.

Phleger, F.B. (1970). Foraminiferal Populations and Marine Marsh Processes. Limnology and Oceanography 15 (4), $522-534$.

Reyment, R.A., Bookstein, F.L., McKenzie, K.G., Majoran, S. (1988). Ecophenotypic Variation in Mutilus pumilus (Ostracoda) from Australia, Studied by Canonical Variate Analysis and Tensor Biometrics. Journal of Micropalaeontology 7 (1): 11-20.

Roberts, L.R., Holmes, J. A., Leng, M.J., Sloane, H.J., Horne, D.J. (2018). Effects of Cleaning Methods Upon Preservation of Stable Isotopes and Trace Elements in Shells of Cyprideis Torosa (Crustacea, Ostracoda): Implications for Palaeoenvironmental Reconstruction. Quaternary Science Reviews, 189, 197-209.

Ruiz, F., Abad, M., Bodergat, A.M., Carbonel, P., RodriguezLázaro, J., González-Regalado, M.L., Toscano, A., Garcia, E.X., Prenda, J. (2013). Freshwater Ostracods as Environmental Tracers. International Journal Environmental Science and Technology, 10, 1115-1128.

Sönmez-Gökçen, N. (1964). Ostrakod'lara Giriş. Maden Tetkik ve Arama Dergisi, 62, 131-141.

Tuncer, A., Tunoğlu, C. (2015 a). Early Pleistocene (Calabrian) Ostracoda Assemblage and Paleoenvironmental Characteristics of the Fevzipaşa Formation, Western Anatolia. Micropaleontology 61 (1-2), 69-83.

Tuncer, A., Tunoğlu, C. (2015b). Geç Erken-Orta Miyosen Yaşlı Söke Formasyonunun Ostrakod Faunası ve Paleoortamsal Karakteristikleri, Söke Havzası, Aydın/Batı Anadolu. Yerbilimleri Dergisi, 36 (3), 97-120

Vardar, S. (2010). Madra Çayı Deltası'nın Holosen Kıyı Paleocoğrafyasının Değerlendirilmesinde Foraminifer ve Ostracod (Crustacea)'ların Bir Ortam Belirleme İndikatörü Olarak Kullanımı. TUCAUM 2010 Ulusal Coğrafya Sempozyumu Bildiri Kitabı. 263 - 273, Ankara.

Vardar, S., Öner, E. (2017). Altınova'da (Ayvalık-Balıkesir) Doğal Çevre Değişmeleri ile Tarih Öncesi Dönemden Günümüze Etkileri. JOA (Journal of Awareness), 2, 181-202.

Vardar, S., Öner, E., İlhan, R. (2017). Bağlararası Höyüğü Çevresinde Paleocoğrafya ve Jeoarkeoloji Araştırmaları (Çeşme İzmir). Türkiye Jeoloji Bülteni, 60 (4), 589-614.

Vardar, S. (2018). Sedimantolojik ve Mikropaleontolojik Verilerle Güzelhisar Çayı Kıyı Ovasının Holosen Paleocoğrafyası. Doğu Coğrafya Dergisi, 23 (39) 131-149 
Yanko, V., Arnold, A.J., Parker, W.C. (1999). Effects of Marine Pollution on Benthic Foraminifera. B. K. Sen Gupta (Ed.), Modern Foraminifera (217-235), Dordrecht: Kluwer Academic Publisher.

Yıldız, S., Öner, E. (2015). Kadıkalesi - Anaia ve Çevresinde (Kuşadası - Aydın) Paleocoğrafya ve Jeoarkeoloji Araştırmaları. C. Şimşek, B. Duman, E. Konakçı (Ed.), Mustafa Büyükkoloancı'ya Armağan içinde (737-758), İstanbul: Ege Yayınları.

WORMS (World Register of Marine Species) 2018. http://www.marinespecies.org/ostracoda/ 3 Aralık 2018. 